\title{
Applied Technologies and Prospects of Conformance Control Treatments in China
}

\author{
Yuzhang Liu', Baojun Bai ${ }^{*}$ and Yefei Wang ${ }^{3}$ \\ 1 Research Institute of Petroleum Exploration and Development, PetroChina, Xueyuan Road 20, Haidian District, Beijing 10083 - China \\ 2 Petroleum Engineering, Missouri University of Science and Technology, 1400 N. Bishop, Rolla, MO 65409 - USA \\ 3 Petroleum Engineering School, Petroleum University of China, Huang Dao, 66 West Changiiang Road, Qingdao, \\ Shandong Province 266555 - China \\ e-mail: livyz@petrochina.com.cn - baib@mst.edu -wangył@upc.edu.cn \\ * Corresponding author
}

\begin{abstract}
Résumé - Technologies et perspectives pour l'amélioration du profil de balayage dans les champs pétroliers matures produits par injection d'eau en Chine - La Chine est le plus grand utilisateur de méthodes chimiques pour l'amélioration du profil de balayage de l'eau pour l'exploitation des champs pétroliers matures. Toute une série de technologies y ont d'ailleurs été créées et déployées avec succès ces dernières années. Cet article commence par présenter les étapes du développement et de la mise en place de ces technologies de contrôle de profil en Chine. Les techniques permettant l'amélioration du profil de balayage sont passées en revue, ainsi que les leçons qui ont pu en être tirées. Le papier aborde ensuite quelques technologies majeures et spécifiques : l'injection de traceurs et l'identification de la présence de chenaux, l'analyse potentiométrique pour l'identification de l'efficacité superficielle de balayage, la technologie de prise de décision fondée sur l'indice de pression (IP) pour le choix d'un puits candidat, une technique de prise de décision complémentaire pour sélectionner des puits candidats et des paramètres de développement, et enfin les principaux produits chimiques utilisés pour la diversion des fluides en profondeur dans le réservoir. De plus, cet article décrit les principes et applications de quelques technologies prometteuses combinant les traitements par méthode chimique avec d'autres procédés EOR/IOR, comme la mise en œuvre de tensioactifs et le traitement de venues d'eau, le contrôle de profil et l'injection de tensioactifs à petite échelle, le traitement à l'acide et le contrôle du profil. Enfin, ce papier résume les problèmes et défis auxquels doivent faire face les champs pétroliers matures balayés à l'eau en Chine. D'après de récents essais sur puits, des analyses de traceurs et de leurs interprétations, et l'expérience en matière de traitement de la gestion de l'eau, il apparaît que les canaux ou les drains de forte perméabilité soient courants dans les champs pétroliers matures balayés à l'eau. Des axes de recherche et des technologies prometteuses sont suggérés.
\end{abstract}

\footnotetext{
Abstract - Applied Technologies and Prospects of Conformance Control Treatments in China China is the largest user of chemical-based conformance control treatments and a series of technologies have been successfully developed and deployed in recent years. This paper first shows the milestones of development and application of conformance control technologies in China. Then integrated conformance control technologies are reviewed followed by the lessons we have learned, and then a few major specific conformance control technologies are addressed, including tracer injection and channels explanation, potentiometric testing to identify areal sweep efficiency, Pressure Index (PI) decisionmaking technology to select well candidate, complementary decision-making technology to select well candidate and design application parameters, and major chemicals for in-depth fluid diversion technologies. In addition, this paper also describes the principles and applications of some promising technologies of combined chemical-based conformance treatment with other EOR/IOR process,
} 


\begin{abstract}
including the combination technology of surfactant and water shutoff, profile control and mini-scale surfactant flooding, acid treatment and profile control treatment. Finally, this paper summarizes the problems and challenges faced by mature water flooded oilfields in China. Based on recent well tests, tracer testing and interpretation, and previous water control treatment experience, it appears that channels or high permeability streaks are common in mature water flooded oilfields. Some research directions and promising technologies are suggested.
\end{abstract}

\section{NOMENCLATURE}

$\begin{array}{ll}c_{t} & \text { Compressibility (1/MPa) } \\ k & \text { Permeability (Darcy) } \\ h & \text { Formation thickness (m) } \\ P I & \text { Pressure index (MPa) }\end{array}$

$P_{0} \quad$ Wellhead water injection pressure before shut in (MPa)

$p(t)$ Real time pressure as a function of time during shut-in of injection well (MPa)

$r_{e} \quad$ Drainage radius $(\mathrm{m})$

$T$ Shut-in Time (minutes)

$W$ Chemical volume $\left(\mathrm{m}^{3}\right)$

$\phi \quad$ Porosity (fraction)

$\mu \quad$ Water viscosity in the formation (cp)

$\beta \quad$ Volume coefficient factor $\left(\mathrm{m}^{3} /(\mathrm{m} \cdot \mathrm{MPa})\right)$

\section{INTRODUCTION}

With the growing need of oil and gas, the life extension of mature hydrocarbon reservoirs has become a real challenge for the coming decades. Water production is a well-recognized problem in depleting reservoirs and water control has become one of the most important targets for oilfield operators [1-3]. Many methods can be used to control water, such as polymer flooding, ASP, gel treatments, and so on [4-6]. Sometimes hydraulic fracturing and acid stimulation also have the role to reduce water cut [7-10]. Broadly speaking, all these methods can be used to control conformance. However, conformance control generally refers to those technologies in which chemical or mechanical methods are used to reduce or block water/gas production resulting from wellbores or high permeability zones/channels/fractures of reservoirs. The conformance control technologies can be used for both injection and production wells. We will use the latter definition in this paper.

Most oilfields in China were discovered in continental sedimentary basins and were characterized by complex geological conditions and high permeability contrasts inside reservoirs [11-15]. In the absence of active aquifer, these oilfields were developed by water flooding from early stage of their development. Many problems, such as sand production, fines migration, mineral dissolution, and so on, resulting from long term of water floods, have made the heterogeneity more serious. Severe vertical and lateral formation heterogeneity has resulted in low sweep efficiency of injected water and excess water production. Conformance control has become one of the most important tasks to control water production and stabilize oil production for the last 30 years.

The tax regulation on chemical application and the increasing demand to oil supply in China have made China uniquely become the largest user of chemical-based Enhanced Oil Recovery (EOR) methods, especially polymer flooding and ASP flooding [16-20]. However early chemical breakthrough has greatly increased the cost of chemical floodings and reduced their economics [21]. Conformance control treatments have also often been applied to reduce the early breakthrough of costly chemicals in these chemical flooding areas, either before, in the middle, or after chemical injection [22-24].

Chemical-based conformance control has been applied since 1950's in China. Different from the application in other countries, currently most treatments focus on injection wells rather than producers in China. Figure 1 gives the number and results of conformance control treatments (both mechanical water shutoff and chemical conformance control treatments) in China. The Data from 1979 to 2000 are estimated from all oilfields in China and after then the results are only from the major oil producer-PetroChina. In total, the oil production totally has been increased by about 146 million barrels from conformance control treatments until 2006. The increase in oil production per treatment was peak at 1986 because most oilfields were in the early and middle water cut stage before that time and water resource was very distinct and clear, and thus mechanical water shutoff was responsible for the high oil increase. After that, the increased oil per treatment has steadily decreased for two reasons: one reason is that most oilfields entered middle to high water cut stage and distinct water zones were not clear and thus chemical-based conformance control dominated treatment results; another reason is that some wells were treated several times and each repeated treatment had the trends for less oil increase.

The wide applications of conformance control technologies have made China accumulate much more experience than other countries. The paper first gives an overview of conformance control application history and technologies in China and emphasis on a few major widely successfully applied technologies and the lessons we learned during the last fifty years' practices. Finally, suggested research and 


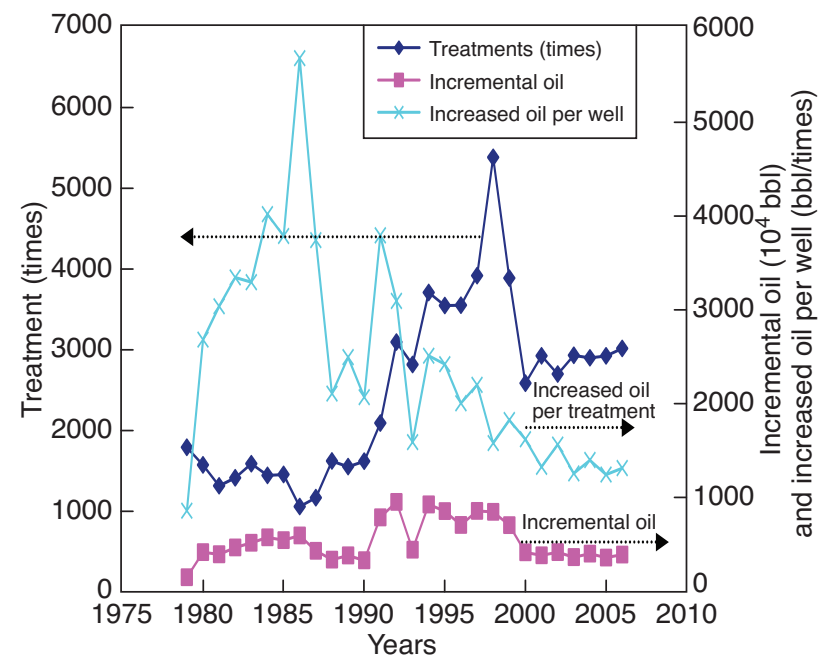

Figure 1

Conformance control treatments and results in China (The Data before 2000 was from all oilfields in China, and after then, the data only from the major oil producer-PetroChina.

application directions of conformance control are provided towards improving the economics and expanding the reservoir conditions where these conformance technologies are technically feasible.

\section{MILESTONES OF CONFORMANCE CONTROL TECHNOLOGIES IN CHINA}

The application of conformance control technologies has experienced more than 50 years in China since 1950s' [11]. A biennial water shutoff \& conformance control symposium has been held to have brought industry experts and academic researchers together to discuss field application cases, exchange new ideas, and shape the future of technology development since 1980. According to each conference topic and related documents, the development of conformance control technologies has six milestones.

\subsection{Unselective Water Shutoff}

One entire isolated zone incurring high water production is plugged or abandoned by injecting a plugging agent in order to allow oil production from other zones, as shown in Figure 2. This technology is mainly used to correct reservoir heterogeneity among isolated layers and the treatment is targeted on the well which has distinctly identified water zone(s) or high water cut zone(s) separated from other oil production zone(s). The plugging agent is mainly injected into a producer by zone isolation method in which a packer or other alternative method is used to separate the target layer from oil producing zones during the injection of a plugging agent. Unselective water shutoff is a quite common technology widely used in the world. The most common plugging agents used in China include traditional cements, ultra-fine cements, resins and strong gels. Their major mechanism to control water is to physically plug the water flow paths to a producer. Cements and ultra-fine cement is often used to plug fractures, wormholes or caves in fractured or channeled reservoirs and the ultra-fine cements are more often used than traditional cement because they can more deeply penetrate into formation [25-30]. The resins and strong gels are often used to seal consolidated non-fracture formation with the more uses of strong gels because of their controllable gelation time. This unselective water shutoff technology was first applied in Liaojunmiao oilfield in 1957 in China [11], and was widely used in the early water cut stage of an oilfield because excess water usually resulted from distinct water zone(s). The technology has still been applied in most oilfields to plug those distinctly identified isolated water zones so far.

\subsection{Profile Control}

Profile control targets on improving the injection profile of an injection well and thus improves sweep efficiency. A plugging agent is injected into an injection well to reduce injection phase absorbing ability of high permeability zones or streaks, as shown in Figure 3. Small amount of strong plugging agents are usually bullheaded into injection wells to seal or partially seal high permeability zones. The technology started to be used in 1980's when most oilfields were at the middle water cut stage with an average water cut of around $50 \%$ and polymer gel technology was just introduced into China. After oilfields entered the middle water cut stage,

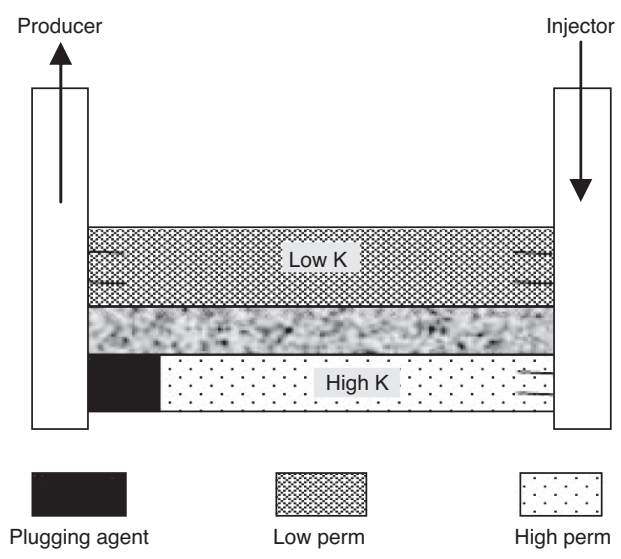

Figure 2

Water shutoff in a producer. 


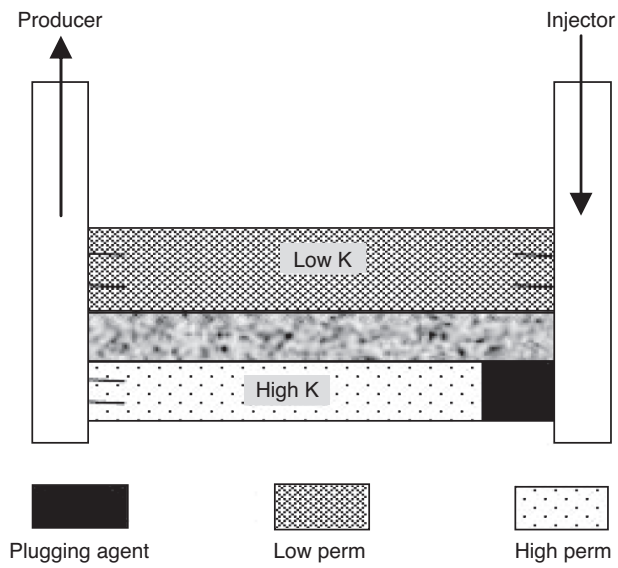

Figure 3

Profile control for an injection well.

unselective water shutoff treatments from production wells usually do not work well because water is mostly produced from multiple zones rather than single zone, and zone isolation is usually impractical for plugging agent injection. Therefore, more attention is paid to injection wells than production wells. Widely applied chemical agents include silicate gels, acrylamide based strong gels, polymer gels, and particles including coal ash, fly ash, lime sludge and so on. Small volume of strong plugging agents, usually less than $100 \mathrm{~m}^{3}$, are usually used for near wellbore treatments. The gel technologies used in China are quite similar as those in other countries.

\subsection{Selective Water Shutoff}

The plugging agents with the capability to reduce permeability to water much more than to oil have been developed and used in oilfields to control water from multiple layers or nonidentified layer for the needs of bullhead injection. The technology started to be used from the early 1990's. Typical agents include oil soluble resins, gels, and emulsions. Oil soluble resins have good rational as selectively water control agents because they form strong plugging once in contact with water while no plugging when contacting with oil, however, produced water may be from multiple zones or cannot be identified where it is from in the high water stage of an producer. Therefore, this product was not used very often. Gels are widely studied for their properties to selectively shut off water and applied in many other countries; however, they are not applied very much in China because of their low success rate [31-38]. A successful technology for selective water shutoff is using $\mathrm{O} / \mathrm{W}$ emulsions by bullhead injection, which was reported to selectively control water production for more than 500 production wells in China $[39,40]$.

\subsection{Integrated Profile Control Treatments for Multiple Wells in One Block}

Multiple injection wells are simultaneously treated to improve the conformance of a whole reservoir, shown in Figure 4. In addition, accessory treatments, such water shutoff in production wells, acid stimulation, plugging removal treatments and recompletion, are often implemented to enhance the integrated treatment results. The technology started from 1990's when more and more oilfields entered middle to high water cut stage and single well profile control treatment showed less and less efficiency. The key to successfully apply the technology is how effectively to select multiple candidates from multiple injection wells. Three-dimension multiple composition reservoir simulators and fast decision-making techniques, PI and RS [41, 42], were successfully developed and deployed to adapt the needs during that time. The decisionmaking techniques can be used to select well candidates and chemical agents, to optimize plugging agent volume and to forecast reservoir performance. The precision of these decision-making techniques is based on the understanding on near wellbore and reservoirs, and thus many problem identification technologies have to be applied or developed to meet the requirement [43-46].

\subsection{In-depth Fluid Diversion}

The technology started from the late 1990's when most oilfields have become mature with less remaining oil near wellbore and dominant interlayer heterogeneity conflict, and many wells were treated for multiple times. Figure 5 show the principle of the method. Figure $5 \mathrm{a}$ is a case of vertical heterogeneity inside a thick layer. If only small amount of plugging agent is placed near wellbore (the

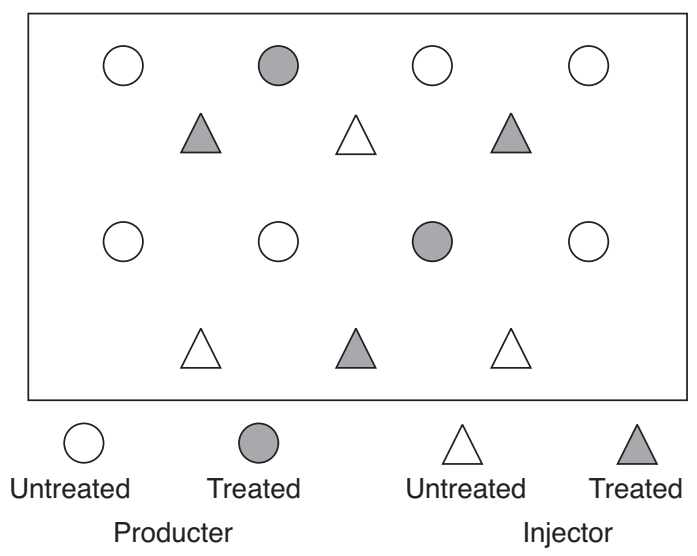

Figure 4

Integrated conformance control treatments in a whole block. 

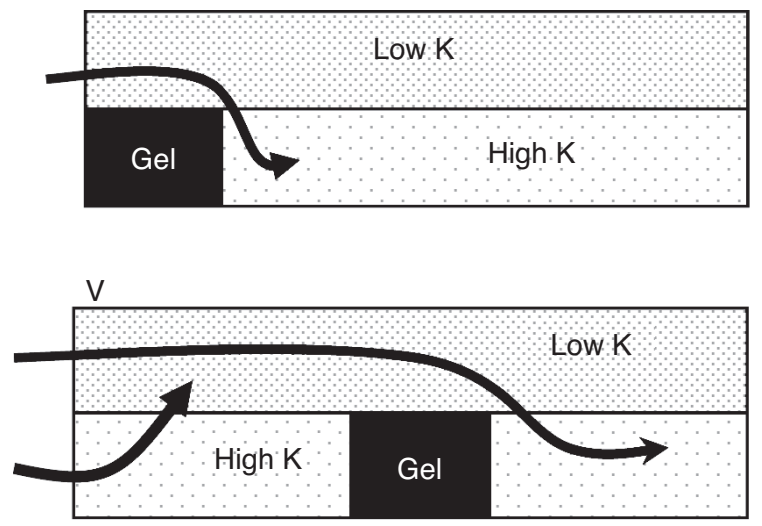

a) Vertical heterogeneity
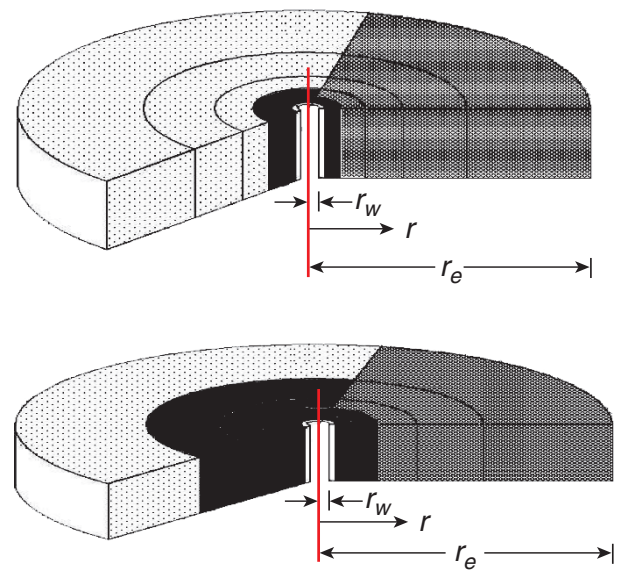

b) Areal heterogeneity

Figure 5

In-depth fluid diversion.

upper figure), the followed water will bypass the gel and then reverse to previous water paths in high permeability portion, so the treatment has little effect on water production and oil increase. Large volume of conformance control treatment, especially if the agents can be placed in the middle between wells, is much more effective to sweep more oil (the lower figure). Figure $5 \mathrm{~b}$ is one example of horizontal heterogeneity. Similarly, if only small volume of plugging agents is injected, the followed water is easy to bypass and go through previous water path and thus large volume and deep penetration are an effective way to improve treatment results. Typical chemicals are weak gel, Preformed Particle Gel (PPG), Colloid Dispersion Gel (CDG), clay gels, and industry wastes. Polymer concentrations usually range from 800 to $2000 \mathrm{mg} / \mathrm{L}$ for weak gel and from 400 to $1000 \mathrm{mg} / \mathrm{L}$ for CDG, both of which are also studied and used in the other part of the world [47-52]. Specifically, China accumulated quite a lot experiences in the use of PPG, clay gels and industry wastes, such as sludge from produced water treatments, oily sludge from oil production and processing.

\subsection{Combination Technologies}

Combination technologies of conformance control and other operations, like acid stimulation and mini-scale surfactant flooding, has been applied since 2000. The combination methods take the advantage of each individual improved oil methods and thus comprehensive results can be obtained [53-57].

\section{REVIEW OF INTEGRATED CONFORMANCE CONTROL TECHNOLOGIES IN CHINA}

Conformance control treatment is not just a matter of chemical agents. Many factors affect whether a conformance control treatment is successful or not. The design and implementation of a conformance control treatment require a systematic integration of geology, petrophysics, reservoir engineering, production engineering, chemistry, facilities and economics. Five aspects have been considered for a successful conformance control treatment:

- selection of well candidates;

- screening or development of chemical agents;

- optimization of treatment parameters;

- field operation and control;

- results evaluation.

Each aspect will be overviewed followed by the lessons we learned in the following.

\subsection{Well Candidate Selection}

\subsubsection{Overview}

Well candidate selection generally follows three steps: initial well candidate screening in a reservoir scale, further selection on an individual well scale and final decision based on economics. It requires teamwork involving in geologists, reservoir engineers, production engineers and field engineers. Initial screening is based on wellbore/reservoir problem identification and comprehensive reservoir evaluation including 
reservoir characterization, remaining oil distribution, formation pressure distribution, well production performance, and interwell connection. Further selection is based on individual information of a selected candidate, including existing surface conditions like the pressure limit of injection pump, wellbore conditions, near wellbore conditions and individual testing and monitoring data, such as injection profiles, production profiles, and tracer transport in different direction. The final decision depends on an economic evaluation, considering available chemical cost, operation costs, and the potential of oil increase and water reduction. A series of techniques have been applied or developed to identify wellbore/reservoir problems, comprehensively evaluate a reservoir, and make decision for well candidate selection. Overall, a good candidate selection is based on:

- reservoir/well bore problem identification;

- comprehensive reservoir evaluation;

- decision making techniques.

\section{Reservoir/Wellbore Problem Identification}

The upmost task before treating a well is to diagnose what is the problem and thus to determine if the problem is really caused by a conformance issue. Many conventional testing techniques have been successfully applied for the purposes, including injection profile log, production log, temperature survey, single-well testing, inter-well tracer monitoring technology, multiple-well testing, and crosswell seismic topographic imaging [43-47]. Table 1 lists the advantage, disadvantage and application of some important methods. In addition, dynamic production data provides valuable information for problem identification. Specifically, China successfully applied inter-well tracer monitoring results to explain the volume and size of channels in a formation [46, 58-60], and also successfully developed and applied the potentimetric method in which potential difference is resulted from the salinity difference between formation water and injected water $[61,62]$.

\section{Comprehensive Reservoir Evaluation}

Reservoir evaluation includes reservoir characterization and reservoir simulation, aiming at knowing reservoir and formation structure, pay zones, petrophysics, production history and remaining oil distribution. Reservoir characterization requires a multidisciplinary team effort. It involves a systematic integration of geological, geophysical and engineering data and improves description of reservoir properties around and between wells. A comprehensive reservoir engineering method has been developed to recognize reservoir characterization and remaining oil distribution for mature oilfields in China. This method integrates 3D reservoir geological modeling and reservoir simulation to characterize a reservoir and to analyze remaining oil and formation pressure distribution [63]. The information from petrophysics, including pore structure and distribution, rock composition and surface properties, oil properties, brine concentration and compositions of formation water, is used to help select chemicals. Remaining oil distribution is used to design the placement of chemicals.

TABLE 1

Common reservoir problem identification methods

\begin{tabular}{|c|c|c|c|c|}
\hline Methods & Description & Advantage & Disvantage & $\begin{array}{l}\text { Application } \\
\text { for conformance control }\end{array}$ \\
\hline Injection profile log & $\begin{array}{l}\text { Measure water injection } \\
\text { profile }\end{array}$ & $\begin{array}{l}\text { Obtain real time water } \\
\text { intake profile with low cost }\end{array}$ & $\begin{array}{l}\text { Only for vertical } \\
\text { heterogeneity }\end{array}$ & $\begin{array}{l}\text { The most important method } \\
\text { to screen well candidates }\end{array}$ \\
\hline Single well testing & $\begin{array}{l}\text { Monitor pressure change } \\
\text { with time after shutting off } \\
\text { or turning on a well }\end{array}$ & $\begin{array}{l}\text { A fast method to determine } \\
\text { average permeability } \\
\text { and identify fractures }\end{array}$ & $\begin{array}{l}\text { It cannot tell } \\
\text { the formation } \\
\text { heterogeneity }\end{array}$ & $\begin{array}{l}\text { A fast method, called PI } \\
\text { decision-making method, } \\
\text { has been widely used }\end{array}$ \\
\hline Multiple well testing & $\begin{array}{l}\text { The flow rate in one well } \\
\text { is changed and the pressure } \\
\text { response is monitored } \\
\text { in adjacent wells }\end{array}$ & $\begin{array}{l}\text { Describe reservoir horizontal } \\
\text { anisotropy, and only requires } \\
\text { a few hours to a few days if } \\
\text { there are super high permeability } \\
\text { channels between wells }\end{array}$ & $\begin{array}{l}\text { Affect the daily } \\
\text { production plan }\end{array}$ & $\begin{array}{l}\text { Mainly used to investigate } \\
\text { the hydraulic communication } \\
\text { between wells but not too often }\end{array}$ \\
\hline Inter-well tracer & $\begin{array}{l}\text { Tracer is injected from } \\
\text { an injector and monitored } \\
\text { from its adjacent producers }\end{array}$ & $\begin{array}{l}\text { Identify well connection } \\
\text { and areal heterogeneity }\end{array}$ & $\begin{array}{l}\text { Data collection } \\
\text { is tedious and } \\
\text { takes time }\end{array}$ & $\begin{array}{l}\text { Commonly used for important } \\
\text { conformance control pilot tests }\end{array}$ \\
\hline $\begin{array}{l}\text { Potentiometric } \\
\text { method }\end{array}$ & $\begin{array}{l}\text { Injected high salinity water } \\
\text { from an injection well and } \\
\text { currents are received from } \\
\text { surface around the well }\end{array}$ & $\begin{array}{l}\text { Identify areal heterogeneity } \\
\text { with low cost }\end{array}$ & $\begin{array}{l}\text { Only for shallow } \\
\text { formation with low } \\
\text { salinity formation } \\
\text { water }\end{array}$ & Used for more than 200 wells \\
\hline $\begin{array}{l}\text { Crosswell seismic } \\
\text { tomographic imaging }\end{array}$ & Seismic method & Identify areal heterogeneity & Expensive & Rare \\
\hline
\end{tabular}




\section{Decision-making Techniques}

Two decision-making techniques have been developed and have been widely deployed in China oilfields to instruct well candidate selection: Pressure Index decision-making technology (PI) and comprehensive decision-making technology (RS). The successful development of PI and RS decision techniques has provided important tools for well selection in China [41, 42].

\subsubsection{Lessons}

Well selection is not just an issue of production engineers or reservoir engineers. It requires teamwork from geologists, reservoir engineers, production engineers, field engineers and facility engineers. For water shutoff treatment in production wells, knowing water resource is the most important task to attack excess water production problem. For conformance control treatments in injection wells, a comprehensive understanding of fracture or high permeability channels/streaks distribution, fault direction and sealing is very important because it provides valuable information for the selection of the area and scale for conformance control. Integrated profile control treatments in a block at one time are much more efficient than single treatments in the high water cut stage because the technology can not only improve local sweep efficiency but aids in changing the fluid flow paths in whole block and thus sweeping more remaining oil in unswept areas or zones. PI and RS decision-making techniques provide quasi-quantitative methods to select well candidates and their accuracy for well selection depends on the input information from measured data and accumulated experience. More cost-effective and less time-consuming methods are needed to be developed for determining the extension and volume of high permeability channels, voids and fractures.

\subsection{Screening or Development of Conformance Control Agents}

\subsubsection{Overview}

The development and evaluation of conformance control agents are the most active part in the research area of conformance control. In early stage of oilfield development, the profile control mainly focused on near wellbore treatments so that strong plugging agents were widely developed and used, such as cement, ultra-fine cement, monomer based polymer gels, silica gels, polymer gels with polymer concentration of $5000-10000 \mathrm{mg} / \mathrm{L}$, and some inorganic particles such as lime sludge, coal ash, and the combination of calcium clay and cement. The injected volume is usually below $100 \mathrm{~m}^{3}$. With the water cut entering middle stage, the middle-strength plugging agents were developed and evaluated, such as lignosulfonate based gel, polymer gels with the polymer concentration of 2000-5000 mg/L, and so on. The injected volume usually ranges from 100 to $500 \mathrm{~m}^{3}$ for relatively deep plugging. Liu [11] summarized the chemical agents for near wellbore treatments and classified them into six types: gels, inorganic particles/particulates, precipitates, foams, microbials and miscellaneous. Detailed information can be referenced in his SPE paper 26991 [38]. The new development after his paper mainly has been focused on the development of in-depth fluid diverting agents because more and more oilfields entered high water cut stage after that, and innerlayer heterogeneity makes near wellbore treatment not very efficient. Therefore, weak plugging agents attracted the most interest for researchers and field operators, and a series of weak plugging agents were developed and evaluated for the deep penetration requirement, including clay gels, polymerclay gels, Colloid Dispersion Gels (CDG), weak gels (BG), Preformed Particle Gels (PPG), Linked Polymer Solution (LPS) and industry wastes, such as oil sludge, limy sludge, and so on [64-76].

\subsubsection{Lessons}

Due to the environmental issues, inconvenient and high cost of fresh water, many operators tended to use produced water to prepare conformance control agents. So it is important to know the produced water effect on the strength and thermal stability of selected conformance control agents. Experimental results even show that fresh produced water usually reduces the strength and thermal stability to gel much more than aged produced water [77].

\subsection{Parameter Design}

\subsubsection{Overview}

Appropriate parameter design is major importance to a successful treatment. Parameters that should be considered include injection pressure or injection rate, injection volume and placement. Injection pressure is often required to control below $80 \%$ of the fracturing pressure of studied formation. Low injection pressure, same as the pressure of water injection, is usually proposed to minimize the penetration of plugging agents into previously unswept areas. Injected volume and placement are determined from well injectivity or reservoir simulation results. Reservoir simulator is often run to optimize gel placement.

\subsubsection{Lessons}

Even though reservoir simulation can be used to more accurately predict a conformance control treatment but it is a time-consuming method. A practical treatment usually need make a fast decision. So previous experience and expert suggestions are still the major source to make decisions for parameter design. In addition, how to reduce the penetration of plugging agents on unswept areas is also a major concern for parameter design. 


\subsection{Field Operation}

\subsubsection{Overview}

Field operation is also one of the important factors for a successful treatment. Operations mainly consider surface facilities, placement control and chemical quality monitoring. Commonly, surface facility is mainly composed of mixing tank with mixer, injection pump, and real-time monitoring system of pressure and injection rate. Two kinds of equipment are usually used: truck-mounted and skid mounted equipment. Placement control mainly relys on the real time monitoring result of pressure and flow rate. Chemical quality monitoring aids in securing quality plugging agents.

\subsubsection{Lessons}

Real time monitoring of pressure and time is very important to a successful treatment. The injection parameters should be adjusted for a better response to a real field or well conditions, especially for particle type of plugging agents. The particle size, concentration and even the volume of particle suspension should be adjusted according to the pressure and flow rate response during treatments. In addition, the samples should be taken for regular check during injection if in-situ gelation system is used.

\subsection{Evaluation of Conformance Control}

\subsubsection{Overview}

The major purposes of a conformance control treatment are to reduce water production and increase oil production rate. For water shutoff in production wells, the main parameters to be evaluated are oil production rate, water cut, production profiles and adjusted recoverable reserves. For profile control, evaluation usually includes: injection profile, injection pressure at previous injection rate, pressure index from stable well test, pressure index from draw down well test, water cut and water/gas production of connected producers. For multiple well treatments in an integrated block, production decline curve analysis is of major importance for the evaluation of comprehensive results.

\subsubsection{Lessons}

Treatment result evaluation is very important for gaining experience which can be used to guide future treatments. Experience is often a major way to design parameter for a conformance control treatment because it provides a fast method to design. Field experience has shown that a successful in-depth treatment is not necessary to accompany with the increase of water injection pressure after treatment.

\section{MAJOR SPECIFIC TECHNIQUES FOR CONFORMANCE CONTROL}

\subsection{Interwell Tracer Monitoring and Explanation Technology}

A tracer is an identifiable substance that can be followed through the course of a process providing information on the pattern of events in the process or on the redistribution of the parts or elements involved [47, 87-88]. Interwell tracer monitoring technique has been widely used to evaluate the areal heterogeneity of a reservoir and to determine flow direction of injected fluid by monitoring tracer concentration change with time. Tracers used in China include radioactive isotopes, fluorite dye, low molecular alcohol and some salt with a distinctive anionic group, such as $\mathrm{SCN}^{-}, \mathrm{NO}_{3}^{-}, \mathrm{Br}^{-}$, and $\mathrm{I}^{-}$. Ideally, selected tracers should have no reaction with fluids and rocks in a reservoir and its concentration is easy to detect. Injection water movement is monitored by analyzing tracer concentration of produced water from adjacent producers. Tracers can be injected as a high concentration slug or continuously over a long period. When slug method is used, a sample should be taken every few hours otherwise some useful information may be lost. However, one issue concerning current tracer technology is that sometimes the sample collection is less frequent, such as every one week or a few days. This way of sampling may cause the loss of some useful data if tracer is produced during the period of no sample collection. A new proprietary monitoring instrument is being developed in China to monitor real-time data which allows more frequent data collection, avoiding conventional restrictions of less frequent data [80].

Interwell tracer testing is used to determine the connectivity between producer and injector, the areal heterogeneity, super-permeability zones or fractures. In particular, numerical software was developed to simulate tracer flow and quantitively determine thief zone thickness, permeability, pore radii and the volume of channels in China. The quantitive analysis results are used to guide the screening and volume design of conformance control agents. Tracer test and analysis results have shown that high permeability streaks or channels widely spread in mature waterflooded reservoirs. For example, tracer tests were used in 12 blocks in Pucheng oilfield, Zhongyuan, SINOPEC, from 1986 to 2005. Results showed:

- the total zone thickness swept by tracers was only $18.3 \%$ of total perforated zone thickness;

- the permeability of swept zones was 20 to 421.8 times their originals, and the pore radius was 2.6 to 12.4 times their originals, and water flow rate was 8.4 to 74 times that at early stage of oilfield development [81]. 


\subsection{Potentiometric Method to Determine Areal Heterogeneity}

This method has been used more than 200 wells to detect areal heterogeneity in China [43]. High salt concentration brine is injected from an injection well, and electric current is created from the same well. The ground electric potentials are measured through electrodes which are placed on several designed locations around the wellbore on the ground surface. The mechanism for the local generation of the currents lies in the potential resulted from the salt concentration difference between injected brine and formation water. The mapping of potential difference, or gradient, can delimit the movement of the injected high salt concentration brine. The methods are usually used in shallow formation and low salinity reservoir. Figure 6 shows one example of potentiometric testing result in the well group of X7-2-F24 in Xingbei oilfield, Daqing [82]. Figure 7 gives the well location of the well group. The high concentration water was injected from the injection well X7-2-F24 and it mainly moved in two directions: one was No. 4 at approximately $60^{\circ}$ and the other one was No. 17 at $255^{\circ}$. Production wells $\mathrm{X} 7-2-23$ and X7-2-25 were located in the two directions,

Figure 6

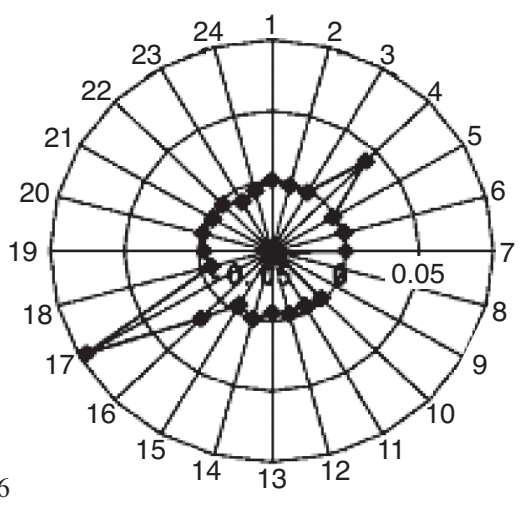

Potentiometric testing result of X-7-2-F-24 group [82].

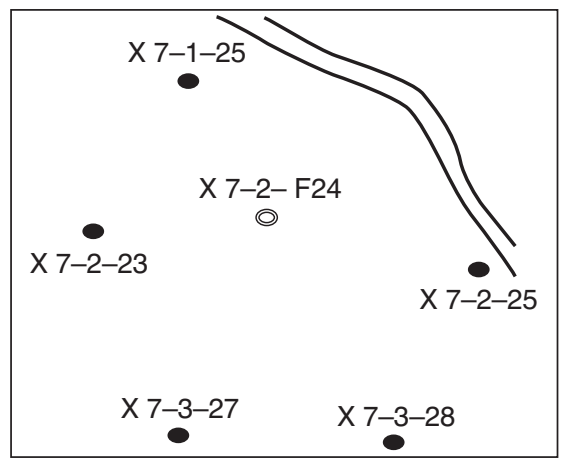

Figure 7

Well location of the tested well group [82]. respectively. It clearly showed that the well (X-7-2-F24) had very severe areal heterogeneity.

\subsection{PI Decision-making Technique for Well Selection}

PI decision-making technique is based on the theory of transient well test and used to fast select candidates from multiple injection wells in a reservoir block [41]. PI can be calculated from wellhead pressure decline curve obtained from recorded real-time pressure with time by shutting in the well, shown in Figure 8.

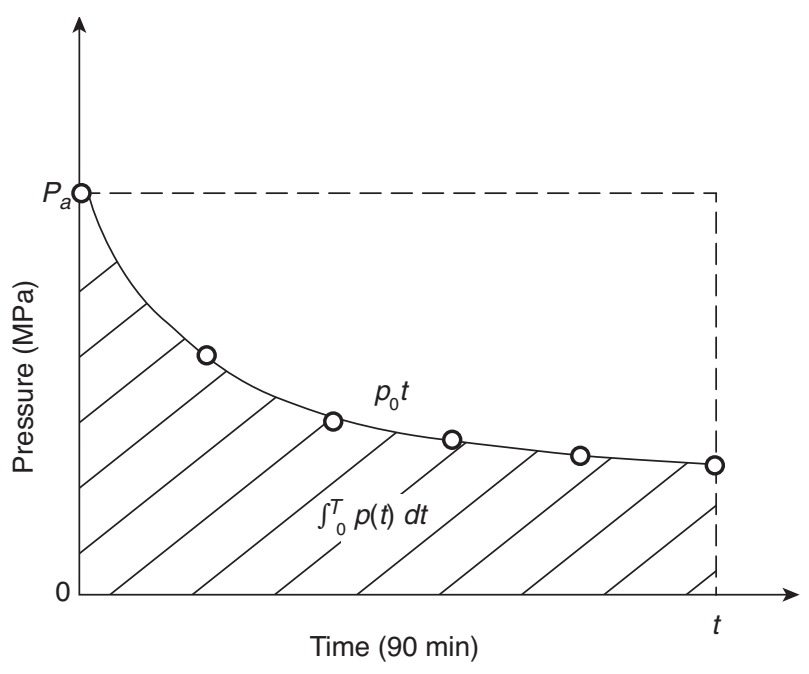

Figure 8

Pressure draw-down curve for PI decision-making.

PI is defined as:

$$
P I=\frac{\int_{0}^{T} p(t)}{T}
$$

where $P I$ : pressure index, $\mathrm{MPa} ; p(t)$ : real time pressure as a function of time during shut-in of injection well; $T$ : Shut-in Time. Ninety minutes is usually designed to have the same standard to compare PI of each well.

PI can also be expressed as follow:

$$
P I=\frac{q \mu}{15 k h} \ln \frac{12.5 r_{e} \varphi \mu c_{t}}{k T}
$$

Equation (2) shows PI is proportional to $q$ and $\mu$, and inverse to $k$ and $h$. Because the $q$ and $h$ are different among wells, Equation (2) was revised as follow:

$$
P I^{\prime}=P I \cdot \frac{h}{q}=\frac{\mu}{15 k} \ln \frac{12.5 r_{e} \varphi \mu c_{t}}{k T}
$$


The $r_{e}, \varphi, \mu, c_{t}$, and $T$ are almost the same for all wells in one block, so PI' only depends on the permeability. To compare among wells, the adjusted $P I$ is defined as follow:

$$
P I(\text { adjusted })=\frac{P I}{(q / h)} \cdot\left(\frac{h}{q}\right)_{\text {avg }}
$$

where, $q / h$ is the flow rate and pay zone thickness of being studied well, and $(h / q)_{\text {avg }}$ is the average $(h / q)$ for all injection wells in the interested block. The adjusted PI is used to screen well candidates.

In practice, $P I$ decision is implemented using the following procedures:

- step 1: Inject water at specified injection rate at least one day before testing;

- step 2: Record water injection rate and injection pressure before shutoff;

- step 3: Shut off well, and record the pressures at different times. Usually one pressure is read every 5 or 10 minutes but more dense data is needed to read (e.g. $0.5 \mathrm{~min}$ or $1 \mathrm{~min}$ ) if the pressure drop is very fast;

- step 4: Draw the plot of pressure (MPa) versus time (min), then PI can be calculated using area method and Equation (1);

- step 5: Calculate adjusted PI using Equation (4);

- step 6: Rank the adjusted PIs for all injection wells in interested block, and select the wells with PI below average PIs as candidates.

$P I$ decision-making technology is used to solve the following five problems:

- determine the necessity of conformance control treatments in a whole block or reservoir. Two criteria are used to determine if a block needs integrated conformance control treatments:

- average $P I$-the smaller average $P I$, the more necessary to be treated. Statistics showed that the block with average $P I$ smaller than $10 \mathrm{MPa}$ needed to be treated;

- the difference between the maximum $P I$ and minimum $P I$-the larger the difference, the more necessary it is to be treated. Statistics showed that the block required integrated conformance control treatments if the difference was above $5 \mathrm{MPa}$;

- screen candidates of injection wells for conformance control: Candidate selection depends on average PI and individual $P I$ of each well. Usually the wells with individual $P I$ smaller than the average $P I$ are selected as candidates for conformance control treatments;

- select chemicals: Chemicals selection depends on:

- formation temperature,

- formation water salinity and composition,

- PI value of candidate,

- cost.
A plugging agent database was built to use for the selection. The smaller an individual well $P I$ is, the stronger plugging agent is needed;

- determine chemical volume: The volume can be determined from the following equation:

$$
W=\beta h \Delta P I
$$

where $\Delta P I$ is the difference between the anticipated $P I$ after the treatment and the $P I$ before the treatment, and $h$ is the net thickness of the well. $\beta$ is volume coefficient and can be determined from either of the following ways:

- trial test: inject plugging agent into a candidate well, and determine the PI difference for injected volume, then use the following equation to calculate the $\beta$ :

$$
\beta=\frac{W}{h \Delta P I^{\prime}}
$$

- if no injection trial test is performed, the $\beta$ can be referenced to the other treated blocks which have similar reservoir conditions with the being studied block;

- determine the frequency of conformance control treatment: Pressure drawdown tests are suggested to be performed for PI calculation every 15 days or 1 month after treatment. Once new $P I$ is reduced to smaller value than average $P I$ of the block, a new treatment is suggested to be carried out.

\subsection{Comprehensive Decision-making Technology for Well Selection and Optimized Design}

A software, called RS, was developed to screen well candidate based on fuzzy logic method [91]. Different from the PI decision-making technique, the method considers three major factors that influence conformance control treatment results, including well injectivity, reservoir heterogeneity and offset production well performance. Each factor is also determined by a few subfactors. Well injectivity is evaluated by pressure index $P I$, water intake index, and apparent water intake index. The reservoir heterogeneity considers permeability heterogeneity coefficient from well logs and injection profile heterogeneity coefficient from water injection profile. The offset production well performance is the function of average water cut, total fluid production rate, remaining oil reserves and recovery factors of the injection well group. It is a three-step decision process as shown in Figure 9: each subfactor group determines a factor, and three factors decide the rank of well candidates, and finally wells will be selected according to the ranking and well conditions (wellbore and surface facility). The key for the method is the weight factor determination for each factor and subfactor when using fuzzy logic method. Expert input and previous field application results provided us a knowledge database for the determination of each weight factor. In addition, the tool 


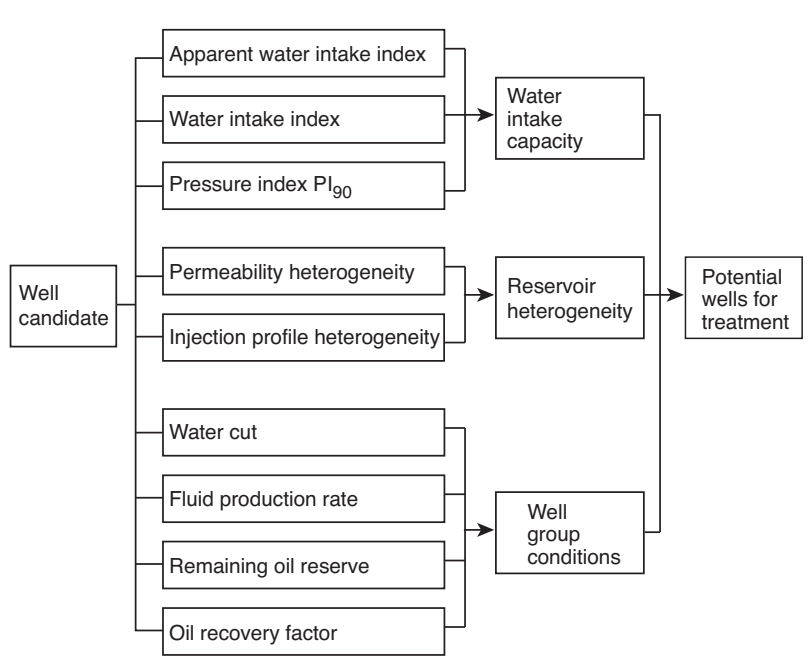

Figure 9

Decision-making for well candidate selection based on fuzzy logic method.

also has the function of conformance control agent selection, injection volume optimization, injection parameter design, and economic forecast. Detailed information can be referred to SPE paper 64731 [42].

\subsection{Major Chemicals for In-depth Fluid Diversion}

\subsubsection{Clay gels}

Clay gels were first used for in-depth fluid diversion treatments in Shengli oilfield in 1991 [85]. After that, many other oilfields, such as Daqing, Dagang, also used the technologies $[84,85]$. The most commonly used clay is sodium montmorilonite. Alternated slugs of polymer and calcium/sodium clay have often been injected as a means to enhance plugging efficiency. Clay gel was widely applied in many oilfields of China in 1990's and early 2000's.

\subsubsection{In-situ Polymer Gels}

In-situ crosslinked polymer gels were the mostly used chemicals for in-depth fluid diversion before PPG was developed because they had the advantages of controllable gelation time, adjustable strength, and good injectivity. An in-situ gelling system is composed of polymer, crosslinker and some other additives. Polymer is usually HPAM, and crosslinkers can be the compounds of $\mathrm{Cr}^{3+}, \mathrm{Cr}^{6+}$, or $\mathrm{Al}^{3+}$, or resin. Additives are used to adjust gelation time, control gel strength and thermo-stability. These compositions react in the formation (mainly temperature effect) to form gel in the areas where they are placed to reduce the flow of followed fluids. Typical in-situ gels for in-depth fluid diversion included weak Bulk Gel (BG) and Colloid Dispersion Gel (CDG). The major difference between them is that $\mathrm{BG}$ is a bulk gel which has higher viscosity than the polymer itself while CDG is a dispersed gel which has lower viscosity than the polymer itself. Tirco company performed a few CDG treatments in Daqing and Shengli oilfields and positive results were reported [86, 87]. Researchers in Nanyang oilfield, SINOPEC, also develop a new CDG using $400 \mathrm{mg} / \mathrm{L}$ of high-molecular-weight polymer and crosslinker $\mathrm{Cr}(\mathrm{Ac})_{3}$ for their $80^{\circ} \mathrm{C}$ reservoir [88]. BG was much more often used than CDG in China because of its higher viscosity and better controllable gelation time. With the fast development of new high-molecular-weight polymers for the requirement of polymer flooding, the polymer concentration used in BG became reduced. The typical polymer concentrations range for BG in China is mainly from 800 to $2000 \mathrm{mg} / \mathrm{L}$ while higher concentration polymers were more often reported in publications from other countries [89-92]. Typical injected BG volumes are from $2000 \mathrm{~m}^{3}$ to $8000 \mathrm{~m}^{3}$. In addition, It is required that the following factors effect on gelation time, gel strength and thermal stability be evaluated before a field application, including:

- chemical compositions;

- pH, salt types and concentrations;

- effect of oxygen and biomaterials;

- fresh and aged produced water;

- shear caused by porous media and pumping;

- core flooding experiments for resistance factor, threshold pressure gradient (minimal injection pressure that water can be injected after gel treatment), and residual resistance factor as a function of fluid types (oil or water) and flow velocity. Per our knowledge, no publication in English was found about fresh produced water effect on gelation time and gel stability. In fact, many experiment results in China indicated fresh produced water had much stronger effect on gelation time and gel properties than aged produced water and this evaluation is of major importance to long period of effectivity of a gel treatment [77, 93-95].

\subsubsection{Preformed Particle Gels}

China developed a new gel, called Preformed Particle Gel (PPG), and has used it for about 2000 wells [96-98]. Table 2 compares PPG and in-situ gelling polymer gels. In summary, PPG has the following advantages:

- PPG is synthesized prior to formation contact, thus overcoming distinct drawbacks inherent in in-situ gelation systems, such as uncontrolled gelation times and variations in gelation due to shear degradation, and gelant compositional changes induced by contact with reservoir minerals and fluids;

- PPG is strength- and size-controlled, environment-friendly, and their stability is not sensitive to reservoirs minerals and formation water salinity; 
- PPG can preferentially enter into fractures or fracturefeature channels while minimizing gel penetration into low permeable hydrocarbon zones/matrix. Gel particles with the appropriate size and properties should transport through fractures or fracture-feature channels, but they should not penetrate into conventional rock or sand. The minimized gel penetration in low permeable areas will also result in significant reductions in the required gel volumes because fracture or fractured-like channels usually comprise less than $10 \%$ of the reservoir volume [99];

- PPG usually has one component during injection. Thus, it does not require many of the injection facilities and instruments that often are needed to dissolve and mix polymer and crosslinker for conventional in-situ gels. The simple injection operation processes and surface facilities can significantly reduce operation and labor costs;

- PPG can be prepared with produced water without influencing gel stability. In contrast, traditional in-situ gels are often very sensitive to salinity, multivalent cations, and $\mathrm{H}_{2} \mathrm{~S}$ in the produced water. This not only can save fresh water but it also can protect our environment. Using large volume of PPG to control conformance was initiated in 1996 by RIPED, PetroChina. The first successful large volume of PPG treatment was in Zhongyuan oilfield, SINOPEC in 1999. Selected reservoir has serious conditions: high temperature $\left(107^{\circ} \mathrm{C}\right)$ and high salinity $(150000 \mathrm{mg} / \mathrm{L})$. So far, About 2000 wells have been treated using PPG or PPG combined with other gels in most oilfields in China, covering both sandstone reservoirs and naturally fractured carbonate reservoirs with temperature from 20 to $110^{\circ} \mathrm{C}$ and formation water salinity from 2000 to $280000 \mathrm{mg} / \mathrm{L}$. The weight of PPG is from 17920 to $100800 \mathrm{lbs}$ and with concentrations from 1000 to $5000 \mathrm{mg} / \mathrm{L}$. For example, PPG has been applied in Daqing oilfield since 2001. Ninety-one wells were treated from 2001 to 2004, and 44 wells from water flooding areas and 47 wells from polymer flooding areas. Injected PPG concentrations were from 3000 to $4500 \mathrm{mg} / \mathrm{L}$, and injection volumes of PPG suspension were from 5000 to $14000 \mathrm{~m}^{3}$. Alternating or continuous injection method was used depending on pressure response during PPG injection. After treatments, average water injection pressure increased about $0.6 \mathrm{MPa}$. Average incremental oil from the 366 producers which connected with treated wells was about $2.6 \mathrm{t} / \mathrm{d} /$ well and water cut decreased about $2.6 \%$, and more than 20000 tons of oil was increased from these treatments. For the application in the polymer flood area, the produced polymer concentration also decreased. PPG has been widely accepted and is seeing more use by operators of Chinese oilfields.

\subsubsection{Sodium Silicate with Hydrochloric Acid}

This agent belongs to the precipitate type of conformance control agents. Sodium silicate and hydrochloric acid solutions separated by a spacer are sequentially injected into a formation. The two chemical solutions usually have low viscosity and preferentially enter high permeability zones/streaks, and react to form plugging in the formation when in contact with each other. Forty-two conformance treatments using this system were implemented in Zhongyuan oilfields from 1997 to 2000 [100]. Over displacement (flush) using $\mathrm{HCl}$ was applied to meet the purposes of stimulating near wellbore and plugging in-depth. The reaction mechanism is as follow:

$$
\mathrm{Na}_{2} \mathrm{SiO}_{3}+2 \mathrm{HCl}=\mathrm{H}_{2} \mathrm{SiO}_{3} \downarrow+2 \mathrm{NaCl}
$$

TABLE 2

PPG advantages over traditional in-situ gel

\begin{tabular}{|c|c|c|c|}
\hline & & PPG & Bulk polymer gel \\
\hline \multicolumn{2}{|c|}{ Chemical reaction } & $\begin{array}{l}\text { Manufactured particle, } \\
\text { no in-situ reactions }\end{array}$ & $\begin{array}{l}\text { Affected by interactions with reservoir rocks } \\
\text { and fluids }\end{array}$ \\
\hline \multicolumn{2}{|c|}{ Viscosity } & Suspension, low viscosity & Bulk chemical solution, high viscosity \\
\hline \multicolumn{2}{|c|}{ Temperature Resistance } & $120^{\circ} \mathrm{C}$ & Depend on polymer, usually below $90^{\circ} \mathrm{C}$ \\
\hline \multicolumn{2}{|c|}{ Salinity Resistance } & Any salt and concentration & Depend on polymer, more sensitive to divalent cationic \\
\hline \multicolumn{2}{|c|}{ Possible damage on formation } & $\begin{array}{l}\text { SMART particle, selectively enter } \\
\text { super-K zones/interval }\end{array}$ & $\begin{array}{l}\text { Like polymer flooding during injection. } \\
\text { Gel may form in low permeability zones }\end{array}$ \\
\hline \multirow{2}{*}{ Preparation of fluids } & Water & Any convenient water & Usually fresh water required \\
\hline & Mixing & Quickly, well disperse & At least 30-60 minutes \\
\hline \multicolumn{2}{|c|}{ Injection Scheme } & Slug, alternated injection of PPG/W & Consecutive, alternated slugs of W/Chemicals not allowed \\
\hline \multicolumn{2}{|c|}{$\begin{array}{l}\text { Pressure monitoring as an indicator } \\
\text { during injection }\end{array}$} & $\begin{array}{l}\text { Quick, good diagnostic to adjust } \\
\text { particle size, strength and conc }\end{array}$ & Not a diagnostic for gel behavior \\
\hline \multicolumn{2}{|c|}{ Costs } & One composition & Polymer + Crosslinker + Additives \\
\hline \multicolumn{2}{|c|}{ Environmental } & Friendly (Salty water) & Fresh water usually required \\
\hline
\end{tabular}




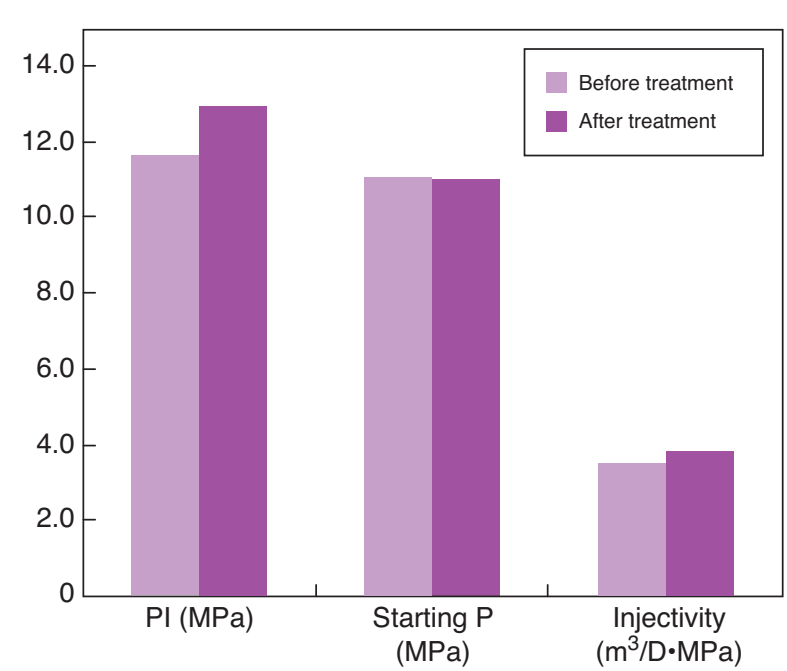

Figure 10

Comparison treament results from 42 treated wells.

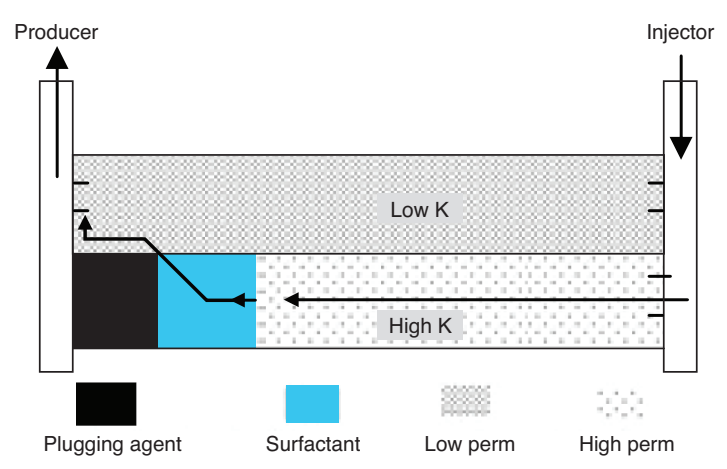

Figure 11

Combination of water shutoff and surfactant soaking in a producer.

Spacer and over-displacement of $\mathrm{HCl}$ have made silicate gel away from wellbore and $\mathrm{HCl}$ can also react with carbonate in reservoir formation to increase permeability near wellbore. Figure 10 compares the average result of Pressure Index $(P I)$, injectivity (water injection rate per wellhead pressure), and starting pressure (the minimal wellhead pressure that water can be injected) before and after conformance control treatments. The slight decrease of injection pressure and starting pressure indicated that the area near wellbore was stimulated. The increase of Pressure Index $(P I)$ indicated the plugging effect of participate because pressure transportation speed was delayed.

\subsubsection{Industry Wastes}

Using industry wastes for conformance control has recently attracted a lot of interest. A great quantity of oil sludge is generated from oil production, transportation and refining each year, one example of its use is for in-depth fluid diversion. Oily sludge is mainly composed of oil, water, $\mathrm{o} / \mathrm{w}$ emulsions, and solids and quite difficult to separate and reuse. The accumulation of oily sludge has posed a serious environmental problem. Additives such as suspension agents, dispersion agents and viscosity thickeners are often added into oil sludge as conformance control agents to extend particle suspension time, increase plugging efficiency, disperse oily drop, and increase penetration depth. The advantages of oily sludge as conformance control agents include:

- good compatibility with formation;

- high temperature resistance;

- high salinity resistance;

- low costs;

- environmental protections.

This method has been used by most of oilfields in China [101-115].

\subsection{Reservoir Simulator for Gel Treatments}

A simulator, called POL-GEL, was successful developed to optimize gel treatments [116], and it is a three-dimension, three-phase (oil, gas, water) and nine-component (oil, gas, water, polymer, crosslinker, gel, mono-valent, divalent, additional sensitive component) model. The simulator can be used to simulate water flooding, polymer flooding and various gel treatments, and it has been verified by the laboratory tests and used for many field applications. Detailed information for the simulator can be referred to SPE paper 64921 [116]. In addition, the knowledge from database which was built in many oilfields based on previous treatments is commonly used to instruct parameter design.

\section{COMBINATION TECHNOLOGIES OF CONFORMANCE CONTROL AND OTHER EOR METHODOLOGIES}

Three combination technologies have been studied and applied in mature oilfields in China, including:

\subsection{Water Shutoff and Mini-scale Surfactant Treatment in a Production Well}

Huff and puff surfactant from a production well is a method to improve oil recovery. However, surfactant mainly enters high permeability zone(s) when injected, and it often takes a long time to shut in wells for surfactant imbibition effect. A combination method was proposed and applied in China [56], and the principle of the method is shown in Figure 11. The method is operated as follows:

- surfactant is injected into a producer and surfactant mostly enters the high permeability portion of open zone(s) during the injection; 
- a water plugging agent is injected and usually goes the same paths as surfactant;

- the well is shut in for a period to cure the plugging agent;

- production is resumed. Incoming displacement water after resuming production will divert surfactant solution from the high permeability to low permeability portion due to crossflow inside the thick heterogeneous zone.

The treatment has the advantages as:

- reducing capillary pressure in low permeability portion due to forced surfactant imbibition in which the force from water displacement speeds up surfactant imbibition;

- increasing the imbibition period because surfactant is not directly produced from high permeability portion;

- increasing plugging efficiency of plugging agents, especially for polymer gels because the injected surfactant displaces the remaining oil in high permeability portion and also changes the formation wettability to more water wet and thus increased plugging efficiency of polymer gels.

\section{2 "2" + "3" Technology}

Profile control is often called an advanced secondary oil recovery technology in China and its key role is to improve sweep efficiency. Surfactant flooding is a tertiary oil recovery technology and its key role is to improve displacement efficiency. A new technology, called "2"+ "3", has been successfully applied to improve both sweep efficiency and displacement efficiency, where "2" refers to profile control and " 3 " refers to tertiary oil recovery technologies, mainly surfactant flooding. The key for the method is called sufficient conformance control and limited quantity of surfactant injection. The method is competed by two steps as follows [117]:

- step 1: Sufficient conformance control treatment: selected plugging agent is injected into formation, and the treatment result should meet two criteria:

- water injection pressure should be greatly improved after treatment,

- the plugging must be sufficient and a new parameter $F D$, which is defined as follow, must be between 0.70 and 0.95:

$$
F D=\frac{\int_{0}^{T} p(t) d t}{p_{0} T}=\frac{1}{p_{0}} \cdot \frac{\int_{0}^{T} p(t) d t}{T}=\frac{P I}{p_{0}}
$$

where, $p_{0}=$ wellhead water injection pressure before shut in, $\mathrm{MPa}$.

If the formation is fully plugged, the wellhead pressure will not change after shutoff, and thus $P I$ is equal to $p_{0}$ and $F D$ is equal to 1 . If the formation still has high permeability streaks, channels or fractures, the wellhead pressure will drop quite fast after shutoff, and thus $F D$ will be close to 0 . Therefore, the $F D$ is an indication of plugging efficiency of injected plugging agents.
- step 2: Limited amount of surfactant flooding: After conformance control is sufficient, limited amount of surfactant is injected to improve displacement efficiency and reduce capillary pressure between oil and water which is a major obstacle for low recovery in low permeability portion in a reservoir. The selection of surfactants considers:

- the compatibility between plugging agents and surfactants,

- ultra-low interfacial tension,

- long term thermostability at reservoir conditions.

The technology has been applied in more than 10 blocks with fractures or super high permeability streaks and very promising results were seen [117-120].

\subsection{Acid Treatment and Profile Control Treatment}

Profile control and acid treatment have completely different roles to enhance oil recovery. Profile control is to plug high flow paths while acid treatment is to increase permeability. However, one problem for acid treatment for mature oilfields is that most acid enters high permeability zones/streaks, which not only reduce acid penetration on targeted low permeability zones but it may also cause the permeability of the high permeability zone to become much higher. To improve acid treatment results, a combination technology of acid stimulation and profile control was proposed and has been successfully applied in mature oilfields in China. In general, a profile control agent was first injected into a well to block high permeability zone/streak or average the water conformance, and then acid is injected. So acid will be diverted and penetrate into the low permeability zone after profile control much more than that without profile control treatment. Paper SPE 89394 show one field application results [121].

\section{RESEARCH AND APPLICATION DIRECTIONS}

\subsection{Identify Channels or Streaks for a Mature Reservoir}

High water cut is a challenging problem for all mature waterflooding oilfields. About $85 \%$ of oil production in PetroChina is from the reservoirs with water cut of more than $80 \%$. Water flooding has made the remaining oil more dispersed in these reservoirs. Heterogeneity inside a thick layer and in areal plane has become more serious. However, it is estimated that about $65-77 \%$ of remaining oil is left in unswept areas and only $23-35 \%$ of remaining oil is confined to the waterflooded area. So sweeping remaining oil from unswept areas is crucial to recovering oil recovery.

Experience indicates that waterflooding has significantly changed the pore structures and physical parameters of reservoirs, and channels, high permeability streaks or 
fractures have become more common in mature oilfields, as evidenced by the following field practices:

- evaluation results from interwell tracer test: Many reservoirs have no initial fractures; however, it took only a few hours to a few days for tracers to breakthrough from adjacent wells in many cases, showing sever channels or streaks between injection and production wells. Tracer explanation results showed these channels were only a few centimeters in thickness but their permeabilities were high to a few hundred Darcy even tens of thousands Darcy [122-130];

- large volume of weak gel treatment: Large volume of weak gel treatment using in-situ gelling systems (usually more than $5000 \mathrm{~m}^{3}$ ) has been used for in-depth fluid diversion in China for many wells. The designed gelling time was usually only a few hours to less than one day but all gelants have been injected into the wells, which were said to have no natural or hydraulic fracture(s), without injectivity problem. However, coreflooding tests in laboratories showed these gels could not flow through the formation with permeability smaller than 10 Darcy [131134], thus, the successful injection of large volume gelling systems indicates the wide spread of high permeability channels or streaks in mature oilfields. In addition, most gel treatments did not increase injection pressure as expected, which also indicated the existence of high permeability channels because weak gel cannot effectively plug channels;

- particle injection: Extensive experiments have been carried out to study particle transport through porous media and results showed the following rules [135]:

$-D_{\text {particle }}>1 / 3 D_{\text {pore throat }}$, particle will form external cake in the inlet of a porous medium and this cake will prevent other particles into the porous medium;

$-3 D_{\text {particle }}<D_{\text {pore throat }}<9 D_{\text {particle }}$, particle will partially enter the porous medium and form internal cake but the penetration depth is only a few centimeter;

$-9 D_{\text {particle }}<D_{\text {pore throat }}$, particle will smoothly move through the porous media without significant plugging.

The rule indicates that a particle can penetrate into the indepth of a reservoir only if its diameter is smaller than $1 / 9$ of pore throat diameter. Many particles, such as clay, limy slurry, coal ash, preformed gel particle, have been successfully injected into wells to control conformance without injectivity problem. The weight of dried particles is from a few tons ( 1 ton $=2240 \mathrm{lbs})$ to a few hundred of tons and particle sizes are up to a few millimeter. However, injectivity is not a problem for most cases. The permeabilities of formations that different sizes of particles can penetrate were calculated, as shown in Table 3 , indicating that the formation might have open fracture(s), caves or voids if it can be penetrated by the particles with a diameter of larger than $0.1 \mathrm{~mm}$.
TABLE 3

Calculated permeability

of a formation that different particle can penetrate

\begin{tabular}{c|c|c}
\hline $\begin{array}{c}\text { Injected } \\
\text { particle } \\
\text { diameter (mm) }\end{array}$ & $\begin{array}{c}\text { Permeability of porous } \\
\text { media at ratio of } 1 / 3 \\
\text { (Darcy) }\end{array}$ & $\begin{array}{c}\text { Permeability of porous } \\
\text { media at ratio of 1/9 } \\
\text { (Darcy) }\end{array}$ \\
\hline 0.061 & 314 & 2825 \\
\hline 0.074 & 462 & 4158 \\
\hline 0.100 & 844 & 7490 \\
\hline 0.154 & 1898 & $1.7 \times 10^{4}$ \\
\hline 0.30 & 7594 & $6.8 \times 10^{4}$ \\
\hline 0.45 & $1.7 \times 10^{4}$ & $1.5 \times 10^{5}$ \\
\hline 0.9 & $6.8 \times 10^{4}$ & $6.2 \times 10^{5}$ \\
\hline 2.0 & $3.4 \times 10^{5}$ & $3.0 \times 10^{6}$ \\
\hline
\end{tabular}

Tracer results and Table 3 can be partially used to explain a couple of concerns that have been arisen from conformance control treatments, including:

- why weak gel can reduce more than $95 \%$ permeability of a core in laboratory but it could not improve starting injection pressure after treatments;

- why gelant with viscosity of hundreds of centipoises can be easily injected into a well without injectivity problem.

In summary, high permeability channels or streaks are very common in mature oilfields in China, but no costeffective method can be used to characterize them even though they are very important for conformance control treatments. Another argument is whether Darcy law can be used to accurately design parameters for a conformance control treatment and predict performance after the treatment. The utmost objective of conformance control treatments is to plug the super-high permeability zones in interested wells or blocks, so the ideal operation is that plugging agents only enter the super-high zones rather than low permeability zones. It might be to better simulate plugging agents flow through super high permeability channels using the equations of fluid flow through tubes rather than Darcy equation. However, more studies need to be carried out to demonstrate if the idea is reasonable.

\subsection{In-depth Fluid Diversion Technologies}

In-situ crosslinker polymer gel and preformed particle gel will remain the major chemicals for in-depth fluid diversion. Although a lot of work has been carried out for both, there still exist some major problems to be solved for better efficiency.

\subsubsection{In-situ Crosslinked Gel}

The following problems should be addressed for in-situ crosslinked gels, including:

- possibility of gelation: the mixture of polymer, crosslinker and additives is squeezed into formation during an in-situ 
gel treatment. Many factors might influence the gelation process and gel quality formed in formation, including the reduced polymer viscosity resulted from shearing from pumping and flowing through pore throats, adsorption and chromatographic separation of chemical components, dilution, $\mathrm{pH}$ and salinity, and so on. Therefore, a systematic study is necessary to evaluate the effect of all possible factors on the gelation time and gel quality for better treatment design;

- the difference of gelation kinetics between dynamic and static conditions. Even though the treated well is usually shut in after gelant is injected, the fluids in the reservoir is moving due to the continuing production of connected producers, and thus the gelation process is dynamic in reservoir conditions. Preliminary research indicated that the dynamics greatly increased the gelation time of a polymer gel and decreased the gel strength [136]. Therefore, the evaluating dynamic effect on crosslinking process is very important for the design of gelation time and gel strength;

- damage of crosslinking system on low permeability unswept areas: gelant behaves as a polymer solution before gelation, and it can much more enter low permeability zones than injected water according to polymer flooding theory. However, the gel will greatly damage those zones if gelant forms gel there. Therefore, it is of major importance to know how to reduce gel damage on unswept areas for improved in-depth gel treatments.

\subsubsection{Preformed Particle Gel}

Traditional PPG is millimeter-sized gel particles, which can not be injected into and move through the porous media with a permeability of smaller than a few Darcy. The new direction in gel particle treatments is to develop softer, small-sized (micro or nano meter size) and swelling-rate controllable particles which will expand the application of PPG to those reservoirs without super high permeability channels or fractures. A few novel small-sized gel particles were developed and applied by international research groups, including microgels [137-138], Bright Water ${ }^{\circledR}$ [139-140] and linked polymer solutions [141-142]. These products have extended the applications of preformed particle gel treatment technology to the reservoirs without fractures or super high permeability zones or streaks. Moreover, the evaluation methods of PPG properties and the PPG transport mechanisms through different porous media should be further investigated to provide valuable information for the optimization design of PPG treatments.

\subsection{Selective Water Shutoff Technology}

Water shutoff treatments have rarely been applied in China recently because oilfields are maturing and water is almost produced from each perforated layer. So how to selectively control water production from a producer is an urgent task.

\subsection{Placement and Optimization}

The design of conformance control treatments need consider both gel properties and reservoir conditions, especially the characterization of fracture, vug and channels/streaks. Proper design and placement must consider the distribution of these super high permeability zones/steaks and gel/gelant transport properties through them. Current reservoir simulators for conformance control treatments can neither meet the requirements, nor can they characterize the process of which channel/streaks may gradually be created during a water flood.

\subsection{Combination Technology of Conformance Control Treatments and Other Tertiary Oil Recovery Technology}

Combination technologies not only can improve sweep efficiency but they can improve displacement efficiency and their pilots have shown promising results. However, further research needs to be performed, such as screening methods to matched chemicals to an application, optimization design methods, etc.

\subsection{Building Database for Conformance Control Treatments}

Many data from conformance control treatments are quite important for the analysis of mature reservoirs, such as well performance before and after treatments, real time response of pressure and injection rate during conformance control agent injection, etc. These valuable data aids in conformance control design and application result forecast.

\section{SUMMARY}

- The milestones of conformance control technologies in China were described and new technologies were developed for the needs of different water cut stages of oilfield development;

- a successful conformance treatment is not just an issue of chemicals, and it requires an integrated technologies: proper candidates selection, appropriate chemicals, optimized of treatment parameters, correct field operation and control, and reasonable result evaluation methods;

- a few major specific technologies were described in details, including:

- the interwell tracer monitoring and explanation technology to explain the channel sizes of water flushed areas, 
- the potentiometric testing technology to identify areal sweep efficiency,

- the PI decision-making technology to select well candidate,

- the complementary decision-making technology to select well candidate and design application parameters,

- the major chemicals for in-depth fluid diversion technologies,

- the problems and challenges that mature oilfields are facing for conformance control treatments were pointed out, and research directions were suggested as follows:

- cost-effective technology to identify super high permeability zone/streaks or fractures for mature oilfields,

- placement control technology for in-depth fluid divertion,

- selective water shutoff technology for unidentified water production,

- reservoir simulation technology to reflect channel effect on conformance control treatment,

- combined technologies to improve comprehensive treatment results,

- knowledge from previous treatments through building database.

\section{REFERENCES}

1 Sydansk R.D., Southwell G.P. (2000) More Than 12 Years' Experience with a Successful Conformance-Control PolymerGel Technology, SPE Prod. Facil. 15, 4, 270-278.

2 Seright R.S. (2003) Washout of Cr(III)-Acetate-HPAM Gels from Fractures, Paper SPE 80200 presented at the SPE International Symposium on Oilfield Chemistry held in Houston, Texas, USA, 5-7 February 2003.

3 Chauveteau G. et al. (2000) Controlling Gelation Time and Microgel Size for Water Shutoff, Paper SPE 59317 presented at the 2000 SPE/DOE Improved Oil Recovery Symposium held in Tulsa, Oklahoma, 3-5 April 2000.

4 Wang D. et al. (2003) Actual Field Data Show that Production Costs of Polymer Flooding can be Lower than Water Flooding, Paper SPE 84849 presented at the SPE International Improved Oil Recovery Conference in Asia Pacific held in Kuala Lumpur, Malaysia, 20-21 October 2003.

5 Song W. et al. (1995) Alkaline-surfactant-polymer Combination Flooding for Improving Recovery of the Oil with High Acid Value, Paper SPE29905 presented at the International Meeting on Petroleum Engineering held in Beijing, PR China, 14-17 November 1995.

6 Grigg R.B., Schechter D.S. (1997) State of the Industry in $\mathrm{CO}_{2}$ Floods, Paper SPE38849 presented at the SPE Annual Technical Conference and Exhibition held in San Antonio, Texas, USA, 5-8 October 1997.

7 Hai Z.X. et al. (1994) Complete Set of Production Techniques of Stabilizing Oil Production while Controlling Water Cut in Low Permeability Reservoirs, J. Petrol. Geol. Oil Field Dev. Daqing 13, $1,53-55$.

8 Wang J.Q. et al. (1995) Production Engineering Role of Reservoir Reconstructive Measures in Stabilizing Oil Production and Controlling Water Cut, J. Petrol. Geol. Oil Field Dev. Daqing 14, 3, 63-64, 15.

9 Zheng Q.Y. et al. (1995) Status and Analysis of Methods and Techniques of Reservoir Stimulation for Enhancing Water Injectivity in Daqing Oil Fields, J. Oilfield Chem. 12, 2, 181-184.

10 Zhang J.C. et al., (2005) Development and Prospect Analysis of Lamadian Oilfield at Extra-High Water Cut Stage, J. Petrol. Geol. Oil Field Dev. Daqing 29, 3, 23-25.

11 Liu X. (Development and Application of the Water Control and Profile Modification Technology in China Oil Fields, Paper SPE 29907 presented at the International Meeting on Petroleum Engineering Held in Beijing, China, 14-17 Nov. 1995.

12 Li G.S. et al. (1996) The Main Results, Technologies, and Resource Potential of Onshore Oil and Gas Exploration in China, J. Fault-Block Oil Gas Field 3, 3, 8-12.

$13 \mathrm{Hu}$ J.Y. et al. (1996) What's New in the Oil-And-Gas-Bearing Basin and Oil Geology Theory of China, J. Fault-Block Oil Gas Field 3, 2, 1-7.

14 Han D.K. et al. (1996) Development Features and Technique Development of Oil \& Gas Fields in China, J. Fault-Block Oil Gas Field 3, 3 1-6.

15 Dong L.R. et al. (1996) Genetic Classification and Distribution Characteristics of Continental Petroleum Systems in China, J.Petrol. Exploration Dev. 23, 1, 1-6.

16 Gang Q.L. et al. (1994) Some Views on improved Oil Recovery in Mature Fields in East China, J. Oil Gas Recovery Technol. 1, 2, 1-7.

17 Gang Q.L. et al. (1998) A Survey of Tertiary Recovery Technology in China, J. Oil Gas Recovery Technol. 5, 4, 1-7.

18 Li J.J. et al. (1999) Development of Tertiary Oil Recovery Technology in China, J. Oil Gas Field Surf. Eng. 18, 2, 8-10.

19 Yang Z.Y., et al. (2004) Current Status and Prospect of Combination Flooding at Home and Abroad, J. Petrol. Geol. Oilfield Dev. Daqing 23, 5, 94-96.

20 Sun H.Q. (2006) Practice and Understanding on Tertiary Oil Recovery in Shengli Oilfield, J. Petrol. Exploration Dev. 33, 3, 262-266.

21 Zhang Y.G. (2003) Contradiction and Countermeasure for Chemical Flooding in Shengli Petroliferous Province, J. Oil Gas Recovery Technol. 10, 6, 53-55.

22 Guo S.P. et al. (1997) The Problem of Oil Recovery Succeeding a Polymer Flooding, J. Acta Petrol. Sin. 18, 4, 49-53.

23 Wang Q.M. et al. (1998) Theoretical Research on Polymer Flooding, J. Petrol. Geol. Oilfield Dev. Daqing 18, 4, 1-5.

24 Zhao F.L. et al. (2001) Combination Technique of Secondary Oil Recovery with Tertiary Oil Recovery and its Progress, $J$. Acta Petrol. Sin. 22, 5, 38-42.

25 Luo Y.et al. (1999) Particulate Type Profile Modification/Water Shutoff Agents Used in Zhongyuan Oilfields, J. Oilfield Chem. 16, 2, 132-133.

26 Liu S.P. (2001) Non-Selective Water Shutoff Agent GWPA-II for Gas Wells and its Uses at Zhongyuan Oilfields, J. Oilfield Chem. 18, 2, 123-126.

27 Liu X.J. et al. (2001) Application of the Super-fine Slurry Plugging Technology in Henan Oilfield, J. Xi'an Petrol. Inst. 16, 6, 62-64.

28 Ren C.J. et al. (2001) Study and Application of Super-fine Slurry Cement, J. Drilling Fluid Completion Fluid 18, 1, 17-20.

29 Zhao C.Q. et al. (2002) Application of Ultra-Fine Cement in Water Shutoff Technology for High Pressure and Low Permeability Oilfield, J. Petrol. Geol. Oilfield Dev. Daqing 21, 1, 65-67. 
$30 \mathrm{Lu}$ W.G. et al. (2004) Improvement and Uses of Superfine Cement Plugging Technology, J. Oilfield Chem. 21, 1, 29-32.

31 Sarkissian J.D. et al. (2005) Lessons Learned from Four Selective Water Shutoff Treatments in Mature Reservoirs in Maracaibo Lake, Paper SPE 96528 presented at Offshore Europe, 6-9 September 2005, Aberdeen, United Kingdom.

32 Kabir A.H. (2001) Chemical Water \& Gas Shutoff Technology An Overview, Paper SPE 72119 presented at SPE Asia Pacific Improved Oil Recovery Conference, Kuala Lumpur, Malaysia, 6-9 October 2001.

33 Kume N. (2003) An Engineering Approach to Predict PostTreatment Well Performance Using Selective Chemical Water Shut-Off Techniques: An RPM Example, Paper SPE 84513 presented at SPE Annual Technical Conference and Exhibition, Denver, Colorado, 5-8 October 2003.

34 Zaitoun A. et al. (1999) Water Shutoff by Relative Permeability Modifiers: Lessons from Several Field Applications, Paper SPE 56740 presented at SPE Annual Technical Conference and Exhibition, Houston, Texas, 3-6 October 1999.

35 Stavland A. (2006) How To Apply a Blocking Gel System for Bullhead Selective Water Shutoff: From Laboratory to Field, Paper SPE 99729 presented at SPE/DOE Symposium on Improved Oil Recovery, Tulsa, Oklahoma, USA, 22-26 April 2006.

36 Faber M.J. et al. (1998) Water Shut-off Field Experience with a Relative Permeability Modification System in the Marmul Field (Oman), Paper SPE 39633 presented at SPE/DOE Improved Oil Recovery Symposium, Tulsa, Oklahoma, 19-22 April 1998.

37 Eoff L. et al. (2001) Structure and Process Optimization for the Use of a Polymeric Relative-Permeability Modifier in Conformance Control, Paper SPE 64985 presented at SPE International Symposium on Oilfield Chemistry, Houston, Texas, 13-16 February 2001.

38 Seright R.S., Liang J. (1994) A Survey of Field Applications of Gel Treatments for Water Shutoff, Paper SPE 26991 presented at SPE Latin America/Caribbean Petroleum Engineering Conference, Buenos Aires, Argentina, 27-29 April 1994.

39 Bai B. et al. (2000) Selective Water Shutoff Technology Study and Application of W/O Emulsions, Paper SPE 59320 presented at SPE/DOE Improved Oil Recovery Symposium, Tulsa, Oklahoma, 3-5 April 2000.

40 Qu Z. X. et al. (2002) Laboratory Evaluation on O/W Emulsion for Selective Water Shutoff, Petrol. Drilling Tech. 31, 4, 56-58.

41 Li Y.K. et al. (1997) Pressure Index Decision Technology for Integrated Profile Control in a Block, J. Univ. Petrol., China (Ed.Nat.Sci.) 21, 2, 39-42.

42 Liu Y.Z., Bai B. (2000) Optimization Design for Conformance Control Based on Profile Modification Treatments of Multiple Injectors in a Reservoir, Paper SPE64731 presented at the SPE International Oil and Gas Conference and Exhibition in China held in Beijing, China, 7-10 November 2000.

43 Zhang J.C. (2003) Interwell Potentiometric Testing Technology, Seismol. Geol. 23, 2, 292-300.

44 Liu J.Z. et al. (2004) Micro-seismic monitoring on direction change of hydro-fractured cracks, Petrol. Exploration Dev. 31, 2, 71-73.

45 Shi Y.G. et al. (2003) Mathematical Model to Explain Channels from Well Testings, Oil Drilling Prod.Technol. 25, 3, 48-50

46 Chen Y.M. et al. (1994) Application of Interwell Tracer Test for Heterogeneous Reservoir Characterization, J. Univ. Petrol., China (Ed.Nat. Sci.) 18, 1, 1-7.

47 Norman C. et al. (2006) A Review of Over 100 Polymer Gel Injection Well Conformance Treatments in Argentina and Venezuela: Design, Field Implementation, and Evaluation, Paper SPE 101781 presented First International Oil Conference and Exhibition in Mexico, Cancun, Mexico, 31 August-2 September 2006.
48 Karaoguz O.K. et al. (2004) Improved Sweep in Bati Raman Heavy-Oil $\mathrm{CO}_{2}$ Flood: Bullhead Flowing Gel Treatments Plug Natural Fractures, Paper SPE 89400 presented at SPE/DOE Symposium on Improved Oil Recovery, Tulsa, Oklahoma, 17-21 April 2004.

49 Wouterlood C.J. et al. (2002) Conformance Improvement with Low Concentration Polymer Gels in a Heterogeneous, Multilayer Reservoir, Paper SPE 75161 presented at SPE/DOE Improved Oil Recovery Symposium, Tulsa, Oklahoma, 13-17 April 2002.

50 Asghari K. et al. (2004) Laboratory Investigation of In-depth Gel Placement for Carbon Dioxide Flooding in Carbonate Porous Media, Paper SPE 90633 presented at SPE Annual Technical Conference and Exhibition, Houston, Texas, 26-29 September 2004.

51 Fielding Jr R.C. et al. (1994) In-Depth Drive Fluid Diversion Using an Evolution of Colloidal Dispersion Gels and New Bulk Gels: An Operational Case History of North Rainbow Ranch Unit, Paper SPE 27773 presented at SPE/DOE Improved Oil Recovery Symposium, Tulsa, Oklahoma, 17-20 April 1994.

52 Diaz D. et al. (2008) Colloidal Dispersion Gels Improve Oil Recovery in a Heterogeneous Argentina Waterflood, Paper SPE 113320 presented at SPE/DOE Symposium on Improved Oil Recovery, Tulsa, Oklahoma, USA, 20-23 April 2008.

53 Song Z.Z. et al. (2003) Separate Zone Plugging and Successive Full Borehole Acidizing in Water Injection Well in Chaheji Oil Field, J. Oilfield Chem. 20, 4, 323-326.

54 Gong X.F. (2004) The Comprehensive Plugging and Acidizing Technology Used for Improving Profile, J. Drilling Prod. Technol. 27, 2, 39-41.

55 Zhao P.C. et al. (2004) Combination of Plugging and Acidization Improves Injection Profile, J. Petrol. Sci. 1, 4, 77-87.

56 Wang Y.F. et al. (2008) Enhanced Oil Production through a Combined Application of Gel Treatment and Surfactant Huff'n'Puff Technology, Paper SPE 112495 presented at the SPE International Symposium and Exhibition on Formation Damage Control, Lafayette, Louisiana, USA, 13-15 February 2008.

57 Shang Z.H. et al. (2007) Development of A New Composite Chemical Oil Displacement Agent and its Application in Block Zhuang 16 of Laohekou Oilfield, J. Chem. Eng. Oil Gas 29, 3, 139-141.

58 Zhao G.Y. (1999) The Application of Interwell Tracer Method in Oilfield Production, J. Petrol. Exploration Dev. 26, 4, 92-95.

59 Han W. et al. (2002) Testing of Breakthrough Flow Channel between Oil and Water Wells by Using Dye Tracer, J. Jianghan Petrol.Inst. 24, 2, 49-50.

$60 \mathrm{Wu}$ Z.D. et al. (2007) Application of Interwell Tracer Detection in Complex Small Fault Block Reservoirs, J. Oil Gas Technol. 29, 3, 237-239.

61 Wang; X.Y., et al. (1999) Identification of Watered out Zones by Normal Distribution Method, J. Well Logging Technol. 23, 1,29-32.

62 Huang H.C. et al. (2002) Several Practical Methods of Identifing Watered-Out Zones in High Salinity Regions, J. Fault-block Oil Gas Field 9, 3, 54-56.

63 Liu H. et al. (2004) Methodologies and Applications of A multiple disciplinary reservoir engineering study for the mature oilfield, Paper SPE87015 presented at SPE Asia Pacific conference on integrated modeling for asset management in Kuala Lumpur, Malaysia, 29-30 March, 2004.

64 Chen T.L. et al. (2005) Microscopic Displacement Mechanism of Weak Gel Flowing in Porous Media, Acta Petrol. Sin. 26, 5,74-77.

65 Li G.B. et al. (1999) The Application of Weak Gels for Profile Modification in CHAHEJI Oil Field, Oil Drilling Prod. Technol. 21, 4, 111-112. 
66 Lai N. (2007) The Appliance of Weak Gels in the Low Permeable Reservoir WU5, Xinjiang Petrol. Sci. Technol. 4, 17, 24-29.

67 Li L.X., Bai B. (1999) Research and Application of Profile Control and Oil Displacement Agent in Deep Reservoir, Oil Drilling Prod. Technol. 21, 6, 51-55.

68 Lv M.S., Zhang H.N. (2004) The Development of Compounded Inorganic Gels, Chem. Eng. Oil Gas 33, 2, 119-120.

69 Ning T.W. (1994) Clay-Based Water Shutoff and Profile Modification Agents Developed and Used in Shengli Oil Fields, Oilfield Chem. 11, 4, 357-361.

70 Sun J. (2003) Experimental Study of Sludge Profile Control Technique Used in Jianghan Oilfield, J. Jianghan Petrol. Inst. 25, 2, 101-102.

71 Chen T.L. (2001) Colloidal Dispersion Gel Used as Permeability Adjusting/Oil Displacing Agent for Sandstone Reservoirs at Fault Block Ma-21, Oilfield Chem. 18, 2, 155-158.

72 Fan Z.Z., Yu Q.S. (2005) Study on Oil-bearing Sludge Profile Control Agent and its Ability Evalutation, J. Zhejiang Univ. 32, $6,658-662$.

73 Sun X.Y. et al. (2004) Profile Modification Technology Using Oil Sludge in the Bin Nan Oilfield, Oil Drilling Prod. Technol. 26, 3, 80-81.

74 Li D.M. (2003) Application and Study on Profile Control Technology Using Oily Sludge, Oil Drilling Prod. Technol. 25, 3, 74-76.

75 Li M.Y., Zheng X.Y., Xiao J.H., Wu Z. (2006) Linked Polymer Solution and its Application in Oil Production, Chemical Industry Press, Beijing, China.

76 Shen G.W. (2003) Study and Application of In-Depth Profile Control Agent for Oily Sluge, Chem. Eng. Oil Gas 32, 6, 381-383.

77 Chen Y.L., Fan C., Yang W.H. (2002) Influence of $\mathrm{Fe}^{2+}, \mathrm{S}^{2-}$, Dissolved Oxygen and $\mathrm{pH}$ on the crosslinking of Polyacrylamide/ $\mathrm{Cr}^{3+} \mathrm{Gel}$, Geol. Sci. Technol. Inf. 21, 2, 61-64.

78 Niu X.L., Zhao G.Y. (2000) Application of Remaining Oil Saturation Testing Technology Using Interwell Tracer in W95 Block, Fault-block Oil Gas Field 7, 4, 48-50.

79 Wu Z.D., Deng G.Y. (2007) Application of Interwell Tracer Detection in Complex Small Fault Block Reservoirs, J. Oil Gas Technol.29, 3, 237-239.

80 Zhu Y.F. (2007) The Application of the Interwell Tracer Monitoring Technology for Oilfields, Meas. Tech. 2000, 4, 74-75.

81 Huang Q.X., Yang Y.C. (2005) Current Development and Future Direction of Profile Control Techniques in Pucheng Oilfield, $J$. Offshore Petrol. 25, 3, 61-65.

82 Liu H. et al. (2006) Granular-Polymer Gel Treatment Successful in the Daqing Oil Field, SPE Prod. Operat. 21, 1, 142-145.

83 Liu Y. Z. et al. (1992) Clay Gel for In-depth Fluid Diversion and its Preparation Method, Chinese Patent: CN92106670.8.

84 Zhao F.L. Zhang G.C. (1994) Selection of Profile Control Agents for Blocks BAN-828 and BAN-9 in DAGANG Oil Field, Oilfield Chem. 11, 4, 314-318.

85 Zhou W., Xie C.Y. (1998) Development and Application of Chemical-based Profile Control Technique in Daqing Oil Field, Petrol. Geol. Oilfield Dev. Daqing 17, 3, 32-34.

86 Harry L. et al. (2006) Successful Field Pilot of In-Depth Colloidal Dispersion Gel (CDG) Technology in Daqing Oilfield, SPE Reserv. Eval. Eng. 9, 5, 664-673.

87 Tian Y., Wang L. (2002) Laboratory Development and Successful Application of a Micelle Dispersions System to EOR, Paper SPE 77795 presented at SPE Asia Pacific Oil and Gas Conference and Exhibition, 8-10 October 2002, Melbourne, Australia.
88 Li Y.T. (2003) Synthesis and Performance of an Organic Chrome Crosslinking Agent for In-depth Profile Control, Oilfield Chem. 25, 6, 46-48.

89 Liu K. (2007) Weak Polymer Gel for EOR in Oil Reservoirs with High Temperature and High Salinity in Shengli, Oilfield Chem. 24, 4, 340-343.

90 Wang Y.F., He L. (2005) A Study on the In-depth Profile Control for IOR in a Reservoir after Polymer Flooding, Oilfield Chem. 22, 4, 349-353.

91 Willhite G.P. et al. (2008) Controlling Water Production Using Gelled Polymer Systems, SPE Reserv. Eval. Eng. 11, 3, 454-465.

92 Sydansk R.D. et al. (2005) Characterization of Partially Formed Polymer Gels for Application to Fractured Production Wells for Water-Shutoff Purposes, SPE Prod. Facil. 20, 3 , 240-249.

93 Dai C.L. (2001) Studies on the Factors Influencing Aqueous Polyacrylamide/Formaldehyde Gel, Oilfield Chem. 18, 1, 24-26.

94 Li J.Q. (2004) pH Effect on Aqueous Cross-linked Gelled Fractured System, Well Test. 13, 1, 42-43.

95 Tao J.Z., Lou T.J., Liu C.X. (1999) Effect of Produced Water Composition on HPAM/Cr3+ Gel, Oilfield Chem. 16, 3, 32-35.

96 Bai B. et al., (2008) Case Study on Preformed Particle Gel for In-Depth Fluid Diversion, Paper SPE113997 presented at the 2008 SPE Improved Oil Recovery Symposium to be held in Tulsa, OK, April 21-23, 2008.

97 Bai B. et al. (2007) Preformed Particle Gel for Conformance Control: Factors Affecting its Properties and Applications, SPE Reserv. Eval.Eng. 10, 4, 415-422.

98 Bai B. et al. (2007) Preformed Particle Gel for Conformance Control: Transport Mechanism through Porous Media, SPE Reserv. Eval. Eng. 10, 2, 176-184.

99 Tang C.J. (2005) Profile modification and profile modification plus oil displacement technique in the high water cut oilfield in Zhongyuan Oilfield, Petrol. Geol. Oilfield Dev. Daqing 24, 1.

100 Yang X.M. et al. (2004) Low Damage Profile Control Technologies, Drilling Prod. Technol. 27, 6, 90-93

101 Wang Y., Su J.D. (2008) Study and Application Oil-Bearing Sludge for Profile Control, J. Oil Gas Technol. 30, 4, 159-160.

102 Sun X.M. (2009) Using Oil-Bearing Sludge to Control Profile in Xingnan of Daqing Oilfield, Oil-Gas Field Surf. Eng. 28, $1,16-17$

103 Xia F.H. et al. (1994) The Use of Ames Test to Monitor The Effect of Composting on The Mutagenicity of Industrial Solid Wastes, J. Nanjing Univ. (Nat. Sci.) 30, 1, 63-68.

104 Wang L.J. et al. (2004) The Hi-tech Research Process of Industrial Solid Waste in China, World Sci.-Tech. Rech. Dev. 26, 1, 17-24.

105 Yang F. et al. (2008) Treatment Technology of Oily Sludge in Long-dong Oilfield, Environ. Prot. Oil Gas Fields 18, 1, 30-32.

106 Li D.M. et al. (2003) Oily Sludge Treatment Technique and Its Application in Henan Oilfield, Environ. Prot. Oil Gas Fields 13, 3, 30-32.

107 Li R.L. et al (2006) Research on Swelling Granular Plugging Agent of Oily Sludge, Environ. Eng. 24, 3, 105-107.

108 Xi F.L. et al. (1998) Preparation and Field Application of Particulated Sludge for Profile Modification, Oilfield Chem. 15, 2, 20-25.

109 Shang Z.H. et al. (2004) Application of Oil-Bearing Sludge Profile Control Technique in Zhuangxi Reservoir, Drilling Prod. Technol. 27, 01, 71-77. 
110 Li D.M. et al. (2006) Application And Research of Profile Control of Oily Sludge, Oil Drilling Prod. Technol. 25, 03, 74-86.

111 Liu G.L. et al. (2007) Synthesis and Performance Evaluation of Oily Sludge Swellable Particulate as In-depth Profile Control Agents, Chem. Eng. Oil Gas 36, 1, 66-70.

112 Shen G.W. et al. (2003) Study and Application of in-Depth Profile Control using Oily Sludge, Chem. Eng. Oil Gas 32, 6, 381-383.

113 Sun J. et al. (2003) Experimental Study of Sludge Profile Control Technique Used in Jianghan Oilfield, J. Jianghan Petrol. Inst. 25, 2 101-103.

114 Lu H.G. et al. (2003) Study on Plugging Capacity of Oil Bearing Sludge as Profile Control Agent, Special Oil Gas Reserv. 10, 4, 73-77.

115 Sun X.J. et al. (1999) Applied Research of Oily Sludge in Oil Field Development, Oil Drilling Prod. Technol. 21, 1, 68-71.

116 Yuan S.Y. et al. (2000) Numerical Simulation Study on Weak Gel Injection, Paper SPE 64921 presented at the SPE Asia Pacific Oil and Gas Conference and Exhibition held in Brisbane, Australia, 16-18 October 2000.

117 Liu J.J. (2002) Pilot Trial of Combination Technique of Secondary and Tertiary Oil Recoveries at Fault Block Tuo11S of Shengtuo Oil Field, J. Oilfield Chem. 19, 1, 59-62.

118 Yu C.M. (2006) Application of Combined Secondary and Tertiary Oil Recovery Techniques in Pucheng Oilfield, $J$. Fault-Block Oil Gas Field 13, 2, 59-61.

119 Mao Y. (2003) Technology Combined Secondary Oil Recovery with Tertiary Oil Recovery for Application and Research in Ng32 Layer in the Northwest of East Chengdong Oilfield, J. Fault-Block Oil Gas Field 10, 6, 57-60.

120 Zhang L.Y. (2002) The Study and Application of " $2+3$ " Enhanced Oil Recovery, J. Inner Mongolin Petrochem. Ind. 27, 2, 103-106.

121 Zhao P.C. et al. (2004) Improve Injection Profile by Combining Plugging Agent Treatment and Acid Stimulation, Paper SPE 89394 presented at the SPE/DOE Symposium on Improved Oil Recovery, Tulsa, Oklahoma, 17-21 April 2004.

122 Wang L.M., Zhang G.P. (2003) Using tracer to Identify Channels and Remaining Oil Distribution, Fault-Block Oil Gas J. 10, 4, 24-26.

123 Liu J.W. et al. (2008) Application of Isotope Tracer Interwell Monitoring Technique in N1 of Shizigou Oilfield, J. Isotopes 21, 1, 54-57.

124 Wang D. et al. (2008) Application of Tracing Flow Measurement Technology in Polymer-injected Profile Test in Gudong Oilfield, Well Logging Technol. 32, 1, 87-89.

125 Wen M. et al. (2008) Application of Tracer Detection Method in the Well Shuang-1, Nat. Gas Ind. 28, 1, 110-112.

126 Dong J.D. et al. (2007) Application of Tracer Flow Survey Technology in Jidong Oilfield, Oil Drilling Prod. Technol. 29, supplement, 106-109.

127 Wu Z.D. et al. (2007) Application of Interwell Tracer Detection in Complex Small Fault Block Reservoirs, J. Oil Gas Technol. 29, 3, 237-239.
128 Yu R.X. et al. (2007) Tracer Technologies used in Oilfields, Ind. Water Treatment 27, 8, 12-15.

129 Chen Y.W. et al. (2007) Combination Interpretation Method for Well-group Tracer Production Curves, J. China Univ. Petrol. (Ed.Nat. Sci.) 31, 4, 74-77.

130 Shi L.H. et al. (2007) The Application of The Micro Material Inter-well Tracing Technology to Recognize High Capacity Channels in Oil Layers, Petrol. Geol. Oilfield Dev. Daqing 26, 4, 130-132.

131 Qi N. et al. (2005) Research on the Techniques of Profiles Control and Water Shutoff Agents I, Drilling Prod. Technol. $\mathbf{2 8}, 01,45-49$.

132 Gao J. et al. (2006) Rheological Properties of High Hygroscopic Profile Modification Gel, J. East China Univ. Sci.Technol.(Nat.Sci.Ed.) 32, 9, 1038-1041.

133 Wang Y.F. et al. (2006) Experimental Study on Gel-based indepth Profile Control Agents for Gudao Oilfield, J. Xi' an Shiyou Univ. (Nat. Sci. Ed.) 21, 1, 46-50.

134 Zhang G.Y. et al. (2007) Research and Application of Chemical Water Plugging Technology in The Well Cb11c-2 in Chengdao Oilfield, Drilling Prod. Technol. 30, 5, 126-127.

135 Maroudas A. (1966) Particle Deposition in Granular Filter Media-2, Filtr. Separat. 3, 2, 115-121.

136 Li L. et al. (2000) Effect of Flowing Shear on Gelation of a Polymer Crosslinking System, Oilfield Chem. 17, 2, 48-51.

137 Chauveteau G., Tabary R., Renard M., Omari A. (2003) Method for preparing microgels of controlled size, Institute of France Petroleum, US Patent 6579909.

138 Cozic C., Rousseau D., Tabary R. (2008) Broadening the Application Range of Water Shutoff Conformance Control Microgels: An Investigation of their Chemical Robustness, Paper SPE 115974 presented at SPE Annual Technical Conference and Exhibition, Denver, Colorado, USA.

139 Frampton H., Morgan J.C., Cheung S.K., Munson L., Chang K.T., Williams D. (2004) Development of a Novel Waterflood Conformance Control System, Paper SPE 89391 presented at SPE/DOE Symposium on Improved Oil Recovery, Tulsa, Oklahoma.

140 Ohms D.S., McLeod J.D., Graff C.J., Frampton H., Morgan J., Cheung S.K., Yancey K.E., Chang K.-T. (2009) Incremental Oil Success from Waterflood Sweep Improvement in Alaska, Paper SPE 121761 presented at SPE International Symposium on Oilfield Chemistry, The Woodlands, Texas.

141 Spildo K., Skauge A., Aarra M.G., Tweheyo M.T. (2008) A New Polymer Application for North Sea Reservoirs, Paper SPE 113460 presented at the 2008 SPE Improved Oil Recovery Symposium held in Tulsa, Oklahoma, USA, 19-23 April 2008.

142 Lin M., Li M., Wang Z., Wu Z. (2009) A Study of Thermal Stability of Linked Polymer Solution, J. Disper. Sci. Technol. 30, 6, 753-756.

Final manuscript received in August 2009 Published online in January 2010

\section{Copyright (C) 2010 IFP Energies nouvelles}

Permission to make digital or hard copies of part or all of this work for personal or classroom use is granted without fee provided that copies are not made or distributed for profit or commercial advantage and that copies bear this notice and the full citation on the first page. Copyrights for components of this work owned by others than IFP Energies nouvelles must be honored. Abstracting with credit is permitted. To copy otherwise, to republish, to post on servers, or to redistribute to lists, requires prior specific permission and/or a fee: Request permission from Documentation, IFP Energies nouvelles, fax.+33147527078, or revueogst@ifpenergiesnouvelles.fr. 